\title{
Phytoplankton from Duas Bocas Reservoir, Espírito Santo State, Brazil (except diatoms)
}

\author{
Alessandra Delazari-Barroso ${ }^{1}$, Célia Leite Sant'Anna ${ }^{2}$ and ${ }^{\dagger}$ Pedro Américo Cabral Senna ${ }^{3}$
}

Received: 8.03.2005; accepted: 17.05.2007

\begin{abstract}
Phytoplankton from Duas Bocas Reservoir, Espírito Santo State, Brazil (except diatoms)). Duas Bocas is a small water supply reservoir $\left(0.51 \mathrm{~km}^{2}\right)$ located in a forested area (Duas Bocas Biological Reserve) $\left(20^{\circ} 18^{\prime} \mathrm{S}\right.$ and $\left.40^{\circ} 28^{\prime} \mathrm{W}\right)$. Phytoplankton community was investigated by samplings weekly taken in the dry (July, 1998) and rainy (March 1999) seasons, at surface, euphotic/afotic boundary, and at the bottom of the water column. A total of 76 taxa was identified with the majority of Chlorophyceae (Chlorococcales) (37.3\%), Conjugatophyceae (Desmidiales) (26.7 \%), and Cyanobacteria (Chroococcales, Nostocales e Oscillatoriales) (22.7 \%). In addition, Euglenophyceae, Dinophyceae, Cryptophyceae, and Chrysophyceae totalized 13.3 \%. The predominant genera were Staurastrum, Staurodesmus, Cosmarium, Desmodesmus, Ankistrodesmus, and Monoraphidium. Regarding to the frequency of occurrence, most of the rare and constant species were belong to Chlorophyceae (Chlorococcales) and Conjugatophyceae (Desmidiales) and Cyanobacteria, respectively. According to the literature, most of the species presented cosmopolitan distribution. Among the identified taxa, 44 species $(57.9 \%)$ are the first citation for the State of Espírito Santo.
\end{abstract}

Key words: floristic survey, vertical distribution, water supply reservoir

RESUMO - (Fitoplâncton do reservatório Duas Bocas, Espírito Santo, Brasil (exceto diatomáceas)). A represa Duas Bocas é um manancial de abastecimento doméstico localizado na Reserva Biológica de Duas Bocas, ES (20 $18^{\prime} \mathrm{S}$ e $\left.40^{\circ} 28^{\prime} \mathrm{W}\right)$. A comunidade fitoplanctônica foi investigada com amostragens semanais durante um mês na estação seca (julho de 1998) e um mês na estação chuvosa (março de 1999), na superfície, profundidade da zona eufótica e fundo da coluna d'água. Foram identificados 76 táxons, com predominância das classes Chlorophyceae (Chlorococcales), contribuindo com 37,3\%, Conjugatophyceae (Desmidiales), com 26,7 \% e Cyanobacteria (Chroococcales, Nostocales e Oscillatoriales), com 22,7\%. Euglenophyceae, Dinophyceae, Cryptophyceae e Chrysophyceae totalizaram 13,3 \%. Staurastrum, Staurodesmus, Cosmarium, Desmodesmus, Ankistrodesmus e Monoraphidium foram os gêneros predominantes. Considerando a freqüência de ocorrência, a maioria das espécies de Chlorophyceae (Chlorococcales) foi considerada como rara, enquanto que dentre as Conjugatophyceae (Desmidiales) e Cyanobacteria, a maioria foi considerada constante. De acordo com a literatura, a maioria das espécies é considerada cosmopolita. Dentre os táxons identificados, 44 espécies (57,9\%) constituem a primeira citação para o Estado do Espírito Santo.

Palavras-chave: distribuição vertical, levantamento florístico, reservatório de abastecimento

\section{Introduction}

The state of Espírito Santo (Brazil) has a large potential for limnological studies related to phytoplanktonic community, because of its plentiful and diverse inland aquatic habitats. Nevertheless, not many studies have been carried out in these ecosystems. Among the very few studied there are a small number of lakes and coastal lagoons (Huszar et al. 1990, Dias Júnior \& Barroso 1998) and one reservoir (Dias Júnior 1998). Lakes have been considered as a good alternative to supply water to attend increasing demands of Espírito Santo's urban and rural populations. Studies on phytoplankton communities have been shown a great importance to portray the limnological status of water supply reservoirs. Among the phytoplankton taxa, Cyanobacteria have been a key group because of its potential for cyanotoxins production in water supply reservoirs. Since there is a public health risks,

1. Faculdade de Saúde e Meio Ambiente-FAESA, Rodovia Serafim Derenzi, 3115, 29030-001 Vitória, ES, Brasil

2. Instituto de Botânica, Caixa Postal 3005, 01061-970 São Paulo, SP, Brasil

3. Universidade Federal de São Carlos, Departamento de Ecologia, Via Washington Luiz, 13560-340 São Carlos, SP, Brasil (in memorian)

4. Corresponding author: delazaribarroso@gmail.com 
Cyanobacteria monitoring has been mandatory according to recent regulations of the Brazilian Ministry of Health (Brazil 2000). In order to support a more effective monitoring program the floristic knowledge of phytoplankton communities is imperative.

The present article is the first report of a floristic survey on the phytoplankton from a water supply reservoir in the State of Espírito Santo. In addition to the floristic survey, the pattern of geographical distribution of the identified taxa is also presented. Diatoms were excluded from this study because they will be presented in another article.

\section{Material and methods}

Duas Bocas Reservoir $\left(20^{\circ} 18^{\prime} \mathrm{S}\right.$ e $\left.40^{\circ} 28^{\prime} \mathrm{W}\right)$ is a small $\left(0.51 \mathrm{~km}^{2}\right)$ and shallow $\left(\mathrm{Z}_{\text {mean }} 4.3 \mathrm{~m}\right)$ water body, which supplies drinking water for part of the Great Vitória, Capital of the State of Espírito Santo. The entire reservoir watershed is protected by a state conservation unity. The Duas Bocas Biological Reserve $\left(29.1 \mathrm{~km}^{2}\right)$ spreads over a low mountain relief (up to $800 \mathrm{~m}$ of altitude) covered by Atlantic forest. The reservoir lies in the lower part of the relief $(200 \mathrm{~m})$ where Naia-açu, Pau Amarelo and Panelas streams outflow. The discharge of the first two streams was estimated as $0.05 \mathrm{~m}^{3} \mathrm{~s}^{-1}$ (Barroso \& Marchioro 1999) and $0.14 \mathrm{~m}^{3} \mathrm{~s}^{-1}$ (Perrone \& Barroso1996), respectively. The summer is hot and wet and winter is cold and dry. Average annual air temperature is $22{ }^{\circ} \mathrm{C}$ and rainfall is $1,500 \mathrm{~mm}$. Even though there are no sources of agriculture, domestic or industrial pollution in the watershed, the tributaries streams input a considerable amount of allocthonous organic matter of forest detritus. Small stands of the free floating aquatic fern Salvinia minima Baker were observed in the riverine area of Pau Amarelo Stream.

Limnological studies in the Reservoir began in 1995 and were related to the physical and chemicals aspects (Delazari \& Barroso 1998) and phytoplankton ecology (Delazari-Barroso 2000). Senna et al. (1999) described a new cyanobacteria species, Cyanodictyon tropicalis Senna, Delazari \& Sant'Anna, in the Reservoir lacustrine zone. According to DelazariBarroso (2000), Duas Bocas Reservoir shows a warm monomictic pattern with strong thermal stratification during summer and winter mixing. The reservoir was classified as meso-eutrophic based on mean annual concentrations of total phosphorus and chlorophyll (Vollenweider \& Kerekes 1980).

Sampling campaigns were carried out in a single sampling station next to the dam and in the deepest part of the Reservoir (figure 1). Water samples were

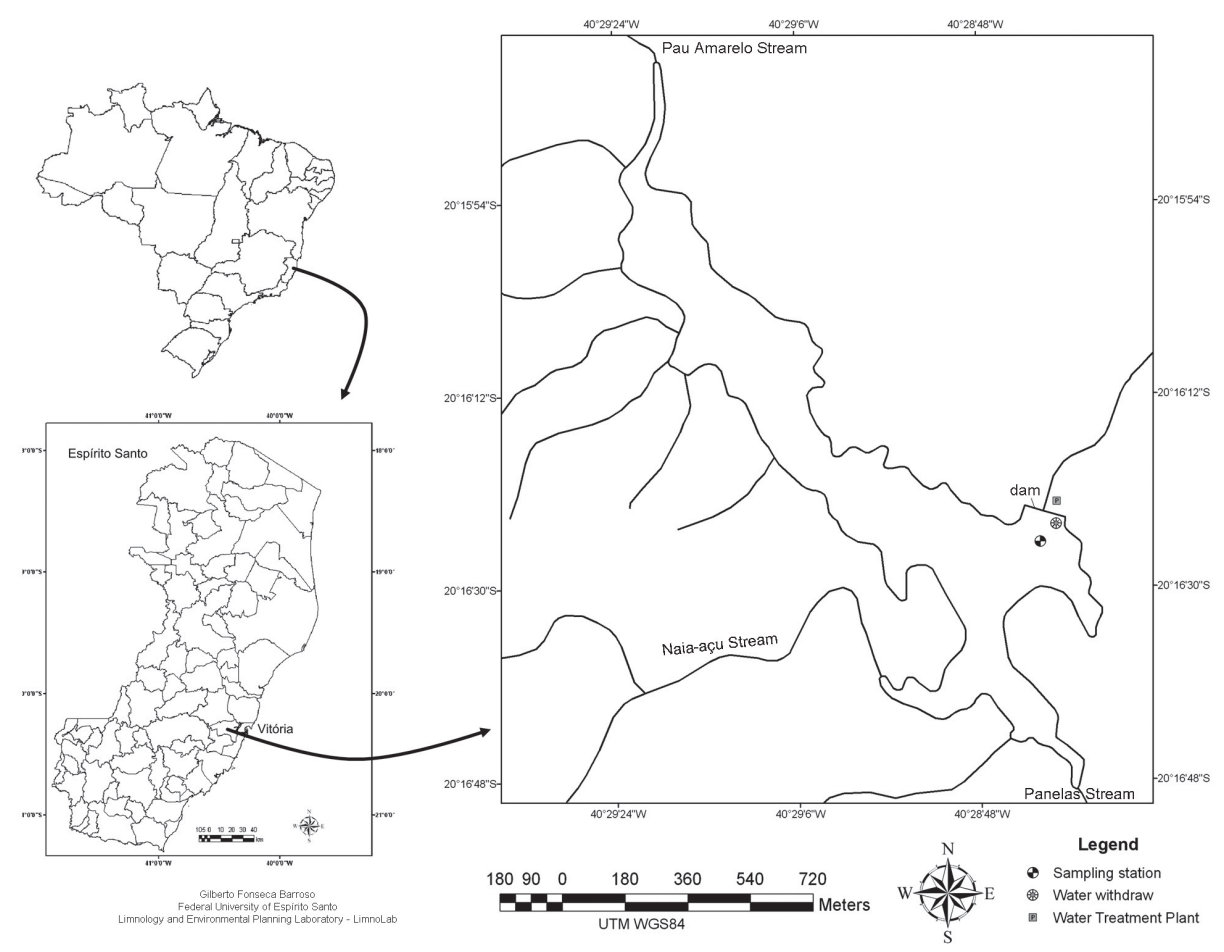

Figure 1. Map of Duas Bocas Reservoir showing the sampling station (right) and the main tributaries. The left inset show the Espírito Santo State (below), in southeastern Brazil (above). 
taken weekly in dry (July, 1998) and rainy (March, 1999) seasons, at surface, euphotic/afotic boundary (4 $\mathrm{m}$ depth), and at the bottom of the water column (9.5 m depth), in a 24 sample set.

Surface samples were taken with a plankton net (mesh size $20 \mathrm{~mm}$ ). Euphotic/afotic boundary and bottom samples were taken with a Van Dorn bottle. All samples were preserved with 4\% formaldehyde. Microscopic investigations were performed using a Zeiss Axioscop microscope equipped with phase contrast and Optovar lens.

The classification systems adopted for the taxonomy were: Komárek \& Fott (1983) and Comas (1996) for Chlorophyceae (Chlorococcales); Föster (1982) for Conjugatophyceae; Anagnostidis \& Komárek (1989) and Komárek \& Anagnostidis (1999, 2005) for Cyanobacteria; Popovský \& Pfiester (1990) for Dinophyceae and Bourrelly $(1981,1985)$ for other classes and Volvocales. Species were classified as rare, common or constant based on the occurrence related to the total number of samples, according to the criteria of Lobo \& Leighton (1986).

\section{Results and Discussion}

Floristic survey resulted in 76 taxa of Cyanobacteria, Chlorophyceae, Conjugatophyceae, Euglenophyceae, Dinophyceae, Cryptophyceae, and Chrysophyceae. Chlorophyceae presented the greatest species number $(36.8 \%$ of the total), followed by Conjugatophyceae (26.3\%), and Cyanobacteria (23.8\%). Euglenophyceae, Dinophyceae, Cryptophyceae, and Chrysophyceae contributed up to $13.1 \%$ of the total (figure 2). $44.4 \%$ of the Cyanobacteria and $45 \%$ of the Conjugatophyceae were considered as constant species. Among Chlorophyceae, $53.6 \%$ of the species was considered rare (table 1). Considering geographical distribution

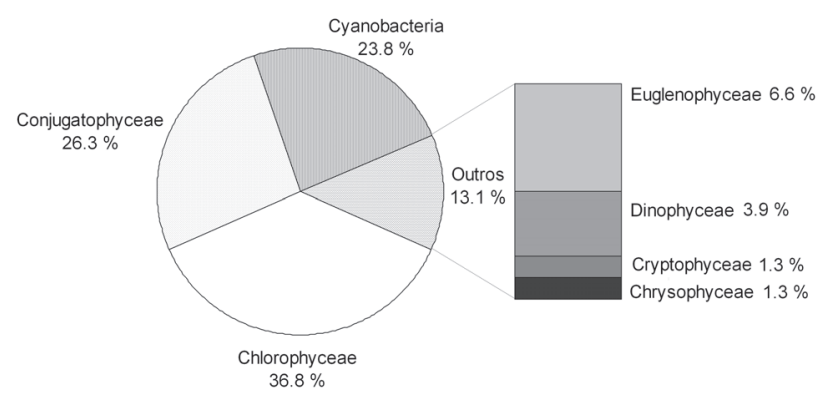

Figure 2. Phytoplanktonic classes (\%) related to the total identified taxa. of studied species, most of the Chlorococcales (60.7\%) and Desmidiales (57.2\%) were regard as cosmopolitan species, while the majority of the Cyanobacteria predominantly occur in tropical (33.4\%) and temperate $(33.3 \%)$ lakes and reservoirs (based on specific literature such Kom. \& Fott 1983; Comas 1996; Prescott et al. 1981, 1982; Kom. \& Anagnostidis 1999, 2005). Among the identified taxa, 44 species (57.9\%) are the first citation for the State of Espírito Santo (table 1).

\section{CYANOBACTERIA \\ CHROOCOCCALES \\ Chroococcaceae}

Chroococcus dispersus (Keissl.) Lemmerm., Ark. Bot. 2: 102. 1904. Chroococcus minor var. dispersus Keissl., Verh. K.K. Zool.-Bot. Ges.Wien 52:311. 1902.

Figure 3

Colonies rounded or irregular, 4-16 or more cells; colonial mucilaginous envelope hyaline, distinct margin; cells spherical, 3.7-4. $\mu \mathrm{m}$ diam.; cell content blue-green, homogeneous (gas vesicles); cell division in three planes.

Herbarium specimens: BRAZIL. EsPíRIto SANTO: Cariacica, Duas Bocas Reservoir, surface, 15-VII-1998, A. Delazari-Barroso s.n. (SP356189).

Chroococcus minimus (Keissl.) Lemmerm., Ark. Bot. 2: 102. 1904. Chroococcus minutus var. minimus Keissl., Verh. K.K. Zool.-Bot. Ges.Wien 51: 394. 1901.

Figure 4

Colonies rounded or irregular, (2-)8 several cells; colonial and individual mucilaginous envelope homogeneous, hyaline; cells spherical, 1.2-1.7 $\mu \mathrm{m}$ diam.; cell content blue-green, homogeneous (gas vesicles); cell division in three planes.

Herbarium specimens: BRAZIL. Espírito SANTO: Cariacica, Duas Bocas Reservoir, surface, 15-VII-1998, A. Delazari-Barroso s.n. (SP356189).

Merismopediaceae

Aphanocapsa koordersii Ström, Nyt. Mag. Naturv. 61: 128. 1923.

\section{Figure 5}

Colonies rounded or elongated; mucilaginous envelope conspicuous, colorless; cells spherical, 
Table 1. Vertical distribution of the Phytoplankton species of the Reservoir Duas Bocas in dry and rainy season and frequency of occurrence. $\mathrm{Sf}=$ surface, $\mathrm{E} / \mathrm{A}=$ euphotic/aphotic boundary, $\mathrm{Bt}=$ bottom; $\mathrm{R}=$ rare, $\mathrm{C}=$ common, $\mathrm{Ct}=$ constant.

\begin{tabular}{|c|c|c|c|c|c|c|c|}
\hline \multirow[t]{2}{*}{ Taxa } & \multirow[b]{2}{*}{ Ocurrence } & \multicolumn{3}{|c|}{ Dry season } & \multicolumn{3}{|c|}{ Rainy season } \\
\hline & & Sf & $\mathrm{E} / \mathrm{A}$ & $\mathrm{Bt}$ & Sf & $\mathrm{E} / \mathrm{A}$ & $\mathrm{Bt}$ \\
\hline \multicolumn{8}{|l|}{ Cyanobacteria } \\
\hline Aphanocapsa koordersi * & $\mathrm{R}$ & & $\mathrm{x}$ & & & $\mathrm{x}$ & \\
\hline Aphanothece smithii $*$ & $\mathrm{R}$ & $\mathrm{x}$ & & & $\mathrm{x}$ & & \\
\hline Chroococcus dispersus * & $\mathrm{R}$ & & $\mathrm{x}$ & & & & \\
\hline Chroococcus minimus $*$ & $\mathrm{R}$ & $\mathrm{x}$ & & & & & \\
\hline Coelosphaerium küetzingianum & $\mathrm{R}$ & $\mathrm{x}$ & & & $\mathrm{x}$ & & \\
\hline Cyanodictyon tropicalis $*$ & $\mathrm{R}$ & & & & & $\mathrm{x}$ & \\
\hline Cylindrospermopsis raciborskii * & $\mathrm{Ct}$ & $\mathrm{x}$ & $\mathrm{x}$ & $\mathrm{x}$ & $\mathrm{x}$ & $\mathrm{x}$ & $\mathrm{x}$ \\
\hline Geitlerinema unigranulatum* & $\mathrm{C}$ & & $\mathrm{x}$ & $\mathrm{x}$ & $\mathrm{x}$ & & \\
\hline Komvophoron minutum * & $\mathrm{R}$ & & & & $\mathrm{x}$ & & \\
\hline Limnothix bicudoi $*$ & $\mathrm{Ct}$ & $\mathrm{x}$ & $\mathrm{x}$ & $\mathrm{x}$ & $\mathrm{x}$ & $\mathrm{x}$ & $\mathrm{x}$ \\
\hline Limnothix redekey * & $\mathrm{Ct}$ & $\mathrm{x}$ & $\mathrm{x}$ & $\mathrm{x}$ & $\mathrm{x}$ & $\mathrm{x}$ & $\mathrm{x}$ \\
\hline Merismopedia punctata & $\mathrm{Ct}$ & $\mathrm{x}$ & $\mathrm{x}$ & $\mathrm{x}$ & $\mathrm{x}$ & $\mathrm{x}$ & $\mathrm{x}$ \\
\hline Merismopedia cf. trolleri $*$ & $\mathrm{C}$ & $\mathrm{x}$ & $\mathrm{x}$ & $\mathrm{x}$ & $\mathrm{x}$ & $\mathrm{x}$ & $\mathrm{x}$ \\
\hline Planktolyngbya limnetica & $\mathrm{Ct}$ & $\mathrm{x}$ & $\mathrm{x}$ & $\mathrm{x}$ & $\mathrm{x}$ & $\mathrm{x}$ & $\mathrm{x}$ \\
\hline Planktolyngbya minor * & $\mathrm{Ct}$ & $\mathrm{x}$ & $\mathrm{x}$ & $\mathrm{x}$ & $\mathrm{x}$ & $\mathrm{x}$ & $\mathrm{x}$ \\
\hline Pseudanabaena moniliformis * & $\mathrm{Ct}$ & $\mathrm{x}$ & $\mathrm{x}$ & $\mathrm{x}$ & $\mathrm{x}$ & $\mathrm{x}$ & $\mathrm{x}$ \\
\hline Synechococcus nidulans $*$ & $\mathrm{Ct}$ & $\mathrm{x}$ & $\mathrm{x}$ & $\mathrm{x}$ & $\mathrm{x}$ & $\mathrm{x}$ & $\mathrm{x}$ \\
\hline Synechococcus sigmoideus * & $\mathrm{C}$ & & & & $\mathrm{x}$ & $\mathrm{x}$ & $\mathrm{x}$ \\
\hline \multicolumn{8}{|l|}{ Chlorophyceae } \\
\hline Ankistrodesmus bernardii & $\mathrm{C}$ & & $\mathrm{x}$ & $\mathrm{x}$ & $\mathrm{x}$ & $\mathrm{x}$ & $\mathrm{x}$ \\
\hline Ankistrodesmus bibraianus $*$ & $\mathrm{R}$ & $\mathrm{x}$ & & & & & \\
\hline Ankistrodesmus fusiformis & $\mathrm{R}$ & & $\mathrm{x}$ & & $\mathrm{x}$ & $\mathrm{x}$ & $\mathrm{x}$ \\
\hline Ankistrodesmus gracilis & $\mathrm{R}$ & & & & $\mathrm{x}$ & & \\
\hline Chlamydomonas pseudotarda * & $\mathrm{R}$ & & & & $\mathrm{x}$ & & \\
\hline Chlorella vulgaris & $\mathrm{Ct}$ & $\mathrm{x}$ & $\mathrm{x}$ & $\mathrm{x}$ & $\mathrm{x}$ & $\mathrm{x}$ & $\mathrm{x}$ \\
\hline Coelastrum proboscideum * & $\mathrm{C}$ & $\mathrm{x}$ & $\mathrm{x}$ & $\mathrm{x}$ & & & \\
\hline Coelastrum pulchrum * & $\mathrm{R}$ & & $\mathrm{x}$ & & & & \\
\hline Desmodesmus bicaudatus & $\mathrm{C}$ & $\mathrm{x}$ & $\mathrm{x}$ & $\mathrm{x}$ & $\mathrm{x}$ & & \\
\hline Desmodesmus perforatus * & $\mathrm{R}$ & $\mathrm{x}$ & & & & & \\
\hline Desmodesmus quadricauda & $\mathrm{C}$ & & $\mathrm{x}$ & $\mathrm{x}$ & $\mathrm{x}$ & & \\
\hline Desmodesmus cf. semipulcher * & $\mathrm{R}$ & & & $\mathrm{x}$ & & & \\
\hline Desmodesmus spinosus & $\mathrm{R}$ & & $\mathrm{x}$ & $\mathrm{x}$ & & & \\
\hline Dictyosphaerium ehrembergianum & $\mathrm{R}$ & & & $\mathrm{x}$ & & & \\
\hline Dictyosphaerium pulchellum & $\mathrm{R}$ & $\mathrm{x}$ & & & & & \\
\hline Didymocystis fina * & $\mathrm{C}$ & $\mathrm{x}$ & & $\mathrm{x}$ & $\mathrm{x}$ & $\mathrm{x}$ & $\mathrm{x}$ \\
\hline Didymocystis inermis * & $\mathrm{R}$ & & & & & $\mathrm{x}$ & \\
\hline Golenkinia radiata & $\mathrm{C}$ & $\mathrm{x}$ & $\mathrm{x}$ & $\mathrm{x}$ & $\mathrm{x}$ & $\mathrm{x}$ & $\mathrm{x}$ \\
\hline Kirchneriella dianae var. major * & $\mathrm{R}$ & $\mathrm{x}$ & & & $\mathrm{x}$ & & \\
\hline Monoraphidium arcuatum & $\mathrm{C}$ & & $\mathrm{x}$ & & $\mathrm{x}$ & $\mathrm{x}$ & $\mathrm{x}$ \\
\hline Monoraphidium contortum & $\mathrm{Ct}$ & $\mathrm{x}$ & $\mathrm{x}$ & $\mathrm{x}$ & $\mathrm{x}$ & $\mathrm{x}$ & $\mathrm{x}$ \\
\hline Monoraphidium griffithii $*$ & $\mathrm{Ct}$ & $\mathrm{x}$ & $\mathrm{x}$ & $\mathrm{x}$ & $\mathrm{x}$ & $\mathrm{x}$ & $\mathrm{x}$ \\
\hline Monoraphidium minutum * & $\mathrm{C}$ & $\mathrm{x}$ & & $\mathrm{x}$ & & $\mathrm{x}$ & \\
\hline Pediastrum tetras & $\mathrm{R}$ & $\mathrm{x}$ & & & $\mathrm{x}$ & & \\
\hline Scenedesmus acuminatus & $\mathrm{C}$ & $\mathrm{x}$ & $\mathrm{x}$ & $\mathrm{x}$ & & & \\
\hline Scenedesmus disciformis & $\mathrm{R}$ & & & & $\mathrm{x}$ & $\mathrm{x}$ & \\
\hline Scenedesmus ecornis * & $\mathrm{Ct}$ & $\mathrm{x}$ & $\mathrm{x}$ & $\mathrm{x}$ & $\mathrm{x}$ & $\mathrm{x}$ & $\mathrm{x}$ \\
\hline Tetrallantos lagerheimii & $\mathrm{R}$ & & $\mathrm{x}$ & & $\mathrm{x}$ & & \\
\hline \multicolumn{8}{|l|}{ Conjugatophyceae } \\
\hline Actinotaenium perminutum $*$ & $\mathrm{Ct}$ & $\mathrm{x}$ & $\mathrm{x}$ & $\mathrm{x}$ & $\mathrm{x}$ & $\mathrm{x}$ & $\mathrm{x}$ \\
\hline Cosmarium asphaerosporum var. strigosum * & $\mathrm{R}$ & & & & $\mathrm{x}$ & $\mathrm{x}$ & \\
\hline Cosmarium cf. capitulum $*$ & $\mathrm{Ct}$ & $\mathrm{x}$ & $\mathrm{x}$ & $\mathrm{x}$ & $\mathrm{x}$ & $\mathrm{x}$ & $\mathrm{x}$ \\
\hline Cosmarium pseudobroomei $*$ & $\mathrm{R}$ & & & & $\mathrm{x}$ & & \\
\hline
\end{tabular}




\begin{tabular}{|c|c|c|c|c|c|c|c|}
\hline \multirow[t]{2}{*}{ Taxa } & \multirow[b]{2}{*}{ Ocurrence } & \multicolumn{3}{|c|}{ Dry season } & \multicolumn{3}{|c|}{ Rainy season } \\
\hline & & $\mathrm{Sf}$ & $\mathrm{E} / \mathrm{A}$ & $\mathrm{Bt}$ & $\mathrm{Sf}$ & $\mathrm{E} / \mathrm{A}$ & $\mathrm{Bt}$ \\
\hline Cosmarium pseudoconnatum & $\mathrm{R}$ & & & & $\mathrm{x}$ & & \\
\hline Staurastrum excavatum $*$ & $\mathrm{Ct}$ & $\mathrm{x}$ & $\mathrm{x}$ & $\mathrm{x}$ & $\mathrm{x}$ & $\mathrm{x}$ & $\mathrm{x}$ \\
\hline Staurastrum forficulatum var. minus * & $\mathrm{R}$ & & & & & $\mathrm{x}$ & \\
\hline Staurastrum laeve & $\mathrm{C}$ & $\mathrm{x}$ & $\mathrm{x}$ & $\mathrm{x}$ & $\mathrm{x}$ & $\mathrm{x}$ & \\
\hline Staurastrum margaritaceum & $\mathrm{R}$ & $\mathrm{x}$ & & & & & \\
\hline Staurastrum micron & $\mathrm{C}$ & $\mathrm{x}$ & $\mathrm{x}$ & $\mathrm{x}$ & & & \\
\hline Staurastrum quadrangulare var. armatum * & $\mathrm{Ct}$ & $\mathrm{x}$ & $\mathrm{x}$ & $\mathrm{x}$ & $\mathrm{x}$ & $\mathrm{x}$ & $\mathrm{x}$ \\
\hline Staurastrum rotula & $\mathrm{R}$ & & & & $\mathrm{x}$ & & \\
\hline Staurastrum smithii $*$ & $\mathrm{Ct}$ & $\mathrm{x}$ & $\mathrm{x}$ & $\mathrm{x}$ & $\mathrm{x}$ & $\mathrm{x}$ & $\mathrm{x}$ \\
\hline Staurastrum tetracerum & $\mathrm{Ct}$ & $\mathrm{x}$ & $\mathrm{x}$ & $\mathrm{x}$ & $\mathrm{x}$ & $\mathrm{x}$ & $\mathrm{x}$ \\
\hline Staurodesmus controversus & $\mathrm{R}$ & $\mathrm{x}$ & & & $\mathrm{x}$ & $\mathrm{x}$ & \\
\hline Staurodesmus dejectus & $\mathrm{R}$ & & $\mathrm{x}$ & & & $\mathrm{x}$ & \\
\hline Staurodesmus indentatus var. rectangularis * & $\mathrm{R}$ & & $\mathrm{x}$ & & & & \\
\hline Staurodesmus cf. crassus $*$ & $\mathrm{Ct}$ & $\mathrm{x}$ & $\mathrm{x}$ & $\mathrm{x}$ & $\mathrm{x}$ & $\mathrm{x}$ & $\mathrm{x}$ \\
\hline Teilingia granulata & $\mathrm{Ct}$ & $\mathrm{x}$ & $\mathrm{x}$ & $\mathrm{x}$ & $\mathrm{x}$ & $\mathrm{x}$ & $\mathrm{x}$ \\
\hline Xanthidium cf. smithii * & $\mathrm{Ct}$ & $\mathrm{x}$ & $\mathrm{x}$ & $\mathrm{x}$ & $\mathrm{x}$ & $\mathrm{x}$ & $\mathrm{x}$ \\
\hline \multicolumn{8}{|l|}{ Euglenophyceae } \\
\hline Euglena limnophila* & $\mathrm{R}$ & & & $\mathrm{x}$ & & & \\
\hline Lepocinclis ovum & $\mathrm{R}$ & & $\mathrm{x}$ & & & $\mathrm{x}$ & \\
\hline Strombomonas ovalis * & $\mathrm{R}$ & & & & & & $\mathrm{x}$ \\
\hline Trachelomonas armata var. steinii & $\mathrm{R}$ & & & $\mathrm{x}$ & & & \\
\hline Trachelomonas volvocina & $\mathrm{R}$ & & & $\mathrm{x}$ & & $\mathrm{x}$ & \\
\hline \multicolumn{8}{|l|}{ Dinophyceae } \\
\hline Peridinium africanum * & $\mathrm{R}$ & $\mathrm{x}$ & & & & & \\
\hline Peridinium gutwinskii * & $\mathrm{C}$ & $\mathrm{x}$ & & & $\mathrm{x}$ & $\mathrm{x}$ & \\
\hline Peridinium umbonatum * & $\mathrm{C}$ & $\mathrm{x}$ & & & $\mathrm{x}$ & $\mathrm{x}$ & \\
\hline \multicolumn{8}{|l|}{ Cryptophyceae } \\
\hline Cryptomonas parapyrenoidifera * & $\mathrm{R}$ & & $\mathrm{x}$ & & & & \\
\hline \multicolumn{8}{|l|}{ Chrysophyceae } \\
\hline Dinobryon sertularia & $\mathrm{R}$ & & & & $\mathrm{x}$ & & \\
\hline
\end{tabular}

*First citation for Espírito Santo State.

1.9-2.5 (-3) $\mu \mathrm{m}$ diam.; cell content pale blue-green, homogeneous; cell division in two planes.

Herbarium specimens: BRAZIL. EspíRITo SANTO: Cariacica, Duas Bocas Reservoir, surface, 15-VII-1998, A. Delazari-Barroso s.n. (SP356189).

Merismopedia punctata Meyen, Neues Syst. Pfl. Physiol. 3: 440. 1839.

Figure 6

Colonies tabulated, until 60 cells; mucilaginous envelope hyaline; cells hemispherical, 2-2.5 (-2.8) $\mu \mathrm{m}$ diam.; cell content blue-green, granulated; cell division in two planes.

Herbarium specimens: BRAZIL. Espírito SAnto: Cariacica, Duas Bocas Reservoir, bottom, 15-VII1998, A. Delazari-Barroso s.n. (SP356190).
Merismopedia cf. trolleri H. Bachm., Zeitschr. f. Hydrol. 1: 10. 1920.

Figure 7

Colonies tabulated, until 64 cells; mucilaginous envelope hyaline; cells oval to slightly spherical, 2.2-2.5(-2.7) $\mu \mathrm{m}$ diam.; cell content blue-green, with aerotopes; cell division in two planes.

Herbarium specimens: BRAZIL. Espírito SANTO: Cariacica, Duas Bocas Reservoir, botton, 15-VII-1998, A. Delazari-Barroso s.n. (SP356190).

Comments: the studied population differs from the typical form by number of cells.

Coelosphaerium küetzingianum Nägeli, Allg. Schweiz. Natur. 10: 54. 1849.

Figure 8 
Colonies microscopic, rounded; mucilaginous envelope hyaline; cells hemispherical, 1.9-2.2(-2.8) $\mu \mathrm{m}$ diam.; distributed near to the colony surface; cell content blue-green, homogeneous; cell division in two planes.

Herbarium specimens: BRAZIL. EspíRIto SANTO: Cariacica, Duas Bocas Reservoir, surface, 15-VII-1998, A. Delazari-Barroso s.n. (SP356189).

Synechococcaceae

Aphanothece smithii Komárk.-Legn. \& Cronberg, Algol. Stud. 72: 25. 1994.

Figure 9

Colonies rounded or irregular; mucilaginous envelope hyaline; cells elliptical, (1.9-)2.3-3.8(-4.2) $\mu \mathrm{m}$ long, (1.9-) 2.1-3.1 $\mu \mathrm{m}$ wide; cell content pale bluegreen, homogeneous; cell division in one plane.

Herbarium specimens: BRAZIL. Espírito SANTO: Cariacica, Duas Bocas Reservoir, surface, 15-VII-1998, A. Delazari-Barroso s.n. (SP356189).

Cyanodictyon tropicalis Senna, Delazari \& Sant'Anna, Algol. Stud. 94: 295. 1999.

Figure 10

Colonies elongated, formed by short or long pseudo-filaments, free or in bundles, oriented more or less in parallel; mucilaginous envelope hyaline; cells elliptical, 1.2-3.1(-3.6) $\mu \mathrm{m}$ long, 0.6-1.2 $\mu \mathrm{m}$ wide; cell content blue-green, rarely granulated; cell division in one plane.

Herbarium specimens: BRAZIL. Espírito SANTO: Cariacica, Duas Bocas Reservoir, surface, 10-III-1999, A. Delazari-Barroso s.n. (SP356195).

Synechococcus nidulans (E.G. Pringsh.) Komárek., Les algues d'eau douce. 3: 119. 1970.

Lauterbornia nidulans E.G. Pringsh., Arch. Mikrobiol. 63:1-6. 1968.

Figure 11

Cells elliptical, solitary, $3.7 \mu \mathrm{m}$ long, $2.5 \mu \mathrm{m}$ wide; cell content pale blue-green, homogeneous; cell division in one plane.

Herbarium specimens: BRAZIL. Espírito SANTO: Cariacica, Duas Bocas Reservoir, surface, 15-VII-1998, A. Delazari-Barroso s.n. (SP356189).
Synechococcus sigmoideus (G. Moore \& N. Carter) Komárek, Arch. Protistenk. 112: 363. 1970. Rhabdoderma sigmoideum G. Moore \& N. Carter, Ann. Missouri Bot. Gard. 10: 393-422. 1923. Figure 12

Cells cilindrical, arcuated, solitary; 1.7-1.9 $\mu \mathrm{m}$ diam.; 9-9.6 $\mu \mathrm{m}$ distance between apex; cell content blue-green, with or without granules; cell division in one plane.

Herbarium specimens: BRAZIL. EsPíRIto SANTO: Cariacica, Duas Bocas Reservoir, surface, 15-VII-1998, A. Delazari-Barroso s.n. (SP356189).

\section{NOSTOCALES}

Nostocaceae

Cylindrospermopsis raciborskii (Wolłosz.) Seenayya \& Subba Raju, Tax. and biol. of blue-green algae. 55. 1972. Anabaena raciborskii Wolłosz., Bull. Int. Acad. Sci. Lett. Cracovie, Ser. B: 684. 1912. Figure 13
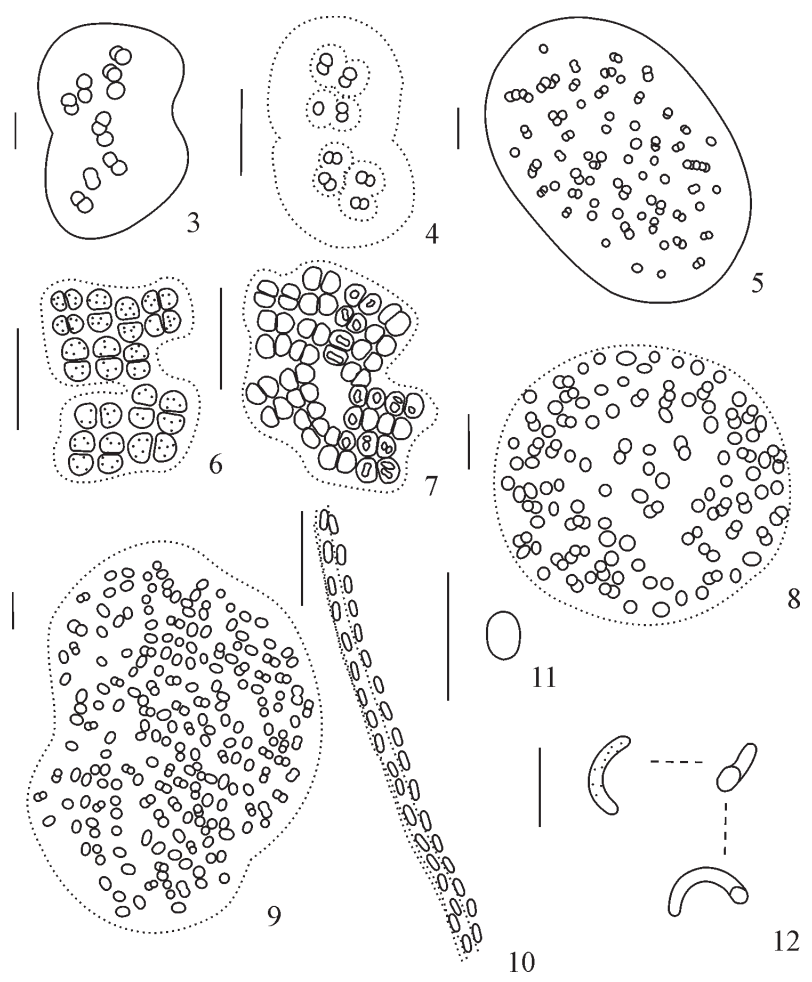

Figure 3. Chroococcus dispersus. 4. C. minimus. 5. Aphanocapsa koordersii. 6. Merismopedia punctata. 7. M. cf. trolleri. 8. Coelosphaerium küetzingianum. 9. Aphanothece smithii. 10. Cyanodictyon tropicalis. 11. Synechococcus nidulans. 12. S. sigmoideus. Scale bars: $10 \mu \mathrm{m}$. 
Trichomes solitary, straight or slightly curved, constricted or not; cells longer than broad, (2.2-)3.1-18.6(-20) $\mu \mathrm{m}$ long, (1.2-)1.7-2.5 $\mu \mathrm{m}$ wide, with aerotopes and granules; apical cell acute-conical; heterocytes always terminal, conical, single, 6.2-9.9 $\mu \mathrm{m}$ long, 1.2-2.5 $\mu \mathrm{m}$ wide; akinetes not observed.

Herbarium specimens: BRAZIL. EspíRIto SANTO: Cariacica, Duas Bocas Reservoir, surface, 10-III-1999, A. Delazari-Barroso s.n. (SP356195).

\section{OSCILLATORIALES}

Borziaceae

Komvophoron minutum (Skuja) Anagnostidis \& Komárek, Algol. Stud. 50-53: 373. 1988. Pseudanabaena minuta Skuja, Symb. Bot. repsal. 9(3): 59.1948.

Figure 14

Trichomes solitary, straight or slightly curved, constricted; cells longer than broad, (4.5-)4.6-6.9(-7.2) $\mu \mathrm{m}$ long, 3.7-4 $\mu \mathrm{m}$ wide; apical cell attenuated, not capitated; cell content blue-green, homogeneous.

Herbarium specimens: BRAZIL. EspíRIto SANTO: Cariacica, Duas Bocas Reservoir, surface, 15-VII-1998, A. Delazari-Barroso s.n. (SP356189).

Pseudanabaenaceae

Planktolyngbya limnetica (Lemmerm.) Komárk.Legn. \& Cronberg, Algol. Stud. 67: 23. 1992. Lyngbya limnetica Lemmerm. Bot. Centralbl. 76: 154. 1898.

Figure 15

Trichomes solitary, straight or slightly curved, not constricted; sheath hyaline, fine; cells longer than wide, (2.2-)3.3-8.4(-8.7) $\mu \mathrm{m}$ long, (1.2-)1.5-1.7(-2.0) $\mu \mathrm{m}$ wide; apical cell cylindrical with rounded end; cross wall with one or more granules; cell content blue-green.

Herbarium specimens: BRAZIL. EspíRITo SANTO: Cariacica, Duas Bocas Reservoir, surface, 15-VII-1998, A. Delazari-Barroso s.n. (SP356189).

Planktolyngbya minor (Geitler \& Rutner) Komárek \& Cronberg, Nova Hedwigia 73: 142. 2001. Lyngbya limnetica f. minor Geitler \& Ruttner, Arch. Hydrobiol. Suppl. 14: 475. 1936.

Figure 16

Trichomes solitary, straight, not constricted; sheath hyaline, fine; cells longer than wide, 3.5-6.4(-6.8) $\mu \mathrm{m}$ long, 0.9-1.0 $\mu \mathrm{m}$ wide; apical cell cylindrical with rounded end; cross wall with one granule; cell content pale blue-green.

Herbarium specimens: BRAZIL. Espírito SANTO: Cariacica, Duas Bocas Reservoir, surface, 10-III-1998, A. Delazari-Barroso s.n. (SP356195).

Geitlerinema unigranulatum (R.N. Singh) Komárek \& M.T.P. Azevedo, Algol. Stud. 99: 51. 2000. Oscillatoria punctata var. unigranulata R.N. Singh, Proc. Indian Acad. Sci. B(9): 68. 1939. Figure 17

Trichomes solitary, straight or slightly curved, not constricted, not attenuated; cells longer than wide, (3.5)3.1-7.0 $\mu \mathrm{m}$ long, (8.1)1.2-1.5 $\mu \mathrm{m}$ wide; apical cell cylindrical with rounded end; cross wall with one granule; cell content blue-green.

Herbarium specimens: BRAZIL. Espírito SANTO: Cariacica, Duas Bocas Reservoir, surface, 22-VII-1998, A. Delazari-Barroso s.n. (SP356191).

Limnothrix bicudoi M.T.P. Azevedo et al., Algol. Stud. 109: 95. 2003.

Figure 18

Trichomes solitary, motile, straight or slightly curved, constricted, not attenuated; cells longer than wide, 3.4-7.7(11.0) $\mu \mathrm{m}$ long, 2.5-3.1 $\mu \mathrm{m}$ wide; apical cell cylindrical with rounded or sometimes widened end, large polar and sometimes central aerotopes and granules; cell content blue-green.

Herbarium specimens: BRAZIL. EsPíRIto SAnto: Cariacica, Duas Bocas Reservoir, surface, 15-VII-1998, A. Delazari-Barroso s.n. (SP356189).

Limnothrix redekei (van Goor) Meffert, Algol. Stud. 50-53: 274. 1988. Oscillatoria redeckei van Goor, Rec. trav. bot. néerland. 258. 1918. Figure 19

Trichomes solitary, straight, constricted, not attenuated; cells longer than wide, (3.6)3.7-8.1(8.7) $\mu \mathrm{m}$ long, 2.2-2.5 $\mu \mathrm{m}$ wide; apical cell cylindrical with rounded end, polar aerotopes; cell content blue-green.

Herbarium specimens: BRAZIL. Espírito SANTO: Cariacica, Duas Bocas Reservoir, surface, 10-III-1999, A. Delazari-Barroso s.n. (SP356195).

Pseudanabaena moniliformis Komárek \& H.J. Kling, Algol. Stud. 61: 27. 1991.

Figure 20 
Trichomes solitary, straight or slightly curved, constricted, not attenuated; cells longer than wide, (2.9)3.1-7.3 $\mu \mathrm{m}$ long, $3.1 \mu \mathrm{m}$ wide; apical cell cylindrical with rounded end; cell content pale bluegreen, homogeneous.

Herbarium specimens: BRAZIL. EspíRIto SANTo: Cariacica, Duas Bocas Reservoir, surface, 15-VII-1998, A. Delazari-Barroso s.n. (SP356189).

\section{CHLOROPHYCEAE \\ CHLOROCOCCALES}

Botryococcaceae

Dictyosphaerium ehrenbergianum Nägeli, Gatt. Einz. Algen. 72: 10. 1849.

Figure 21

Colonies rounded or elongated, groups of 4 cells, united by mucilaginous stalks; cells oblong, (7.4-)7.6-8.7 $\mu \mathrm{m}$ long, 6.2-9.9(-10.5) $\mu \mathrm{m}$ wide; chloroplast cup shaped, with one pyrenoid.

Herbarium specimens: BRAZIL. Espírito SAnto: Cariacica, Duas Bocas Reservoir, surface, 15-VII-1998, A. Delazari-Barroso s.n. (SP356189).

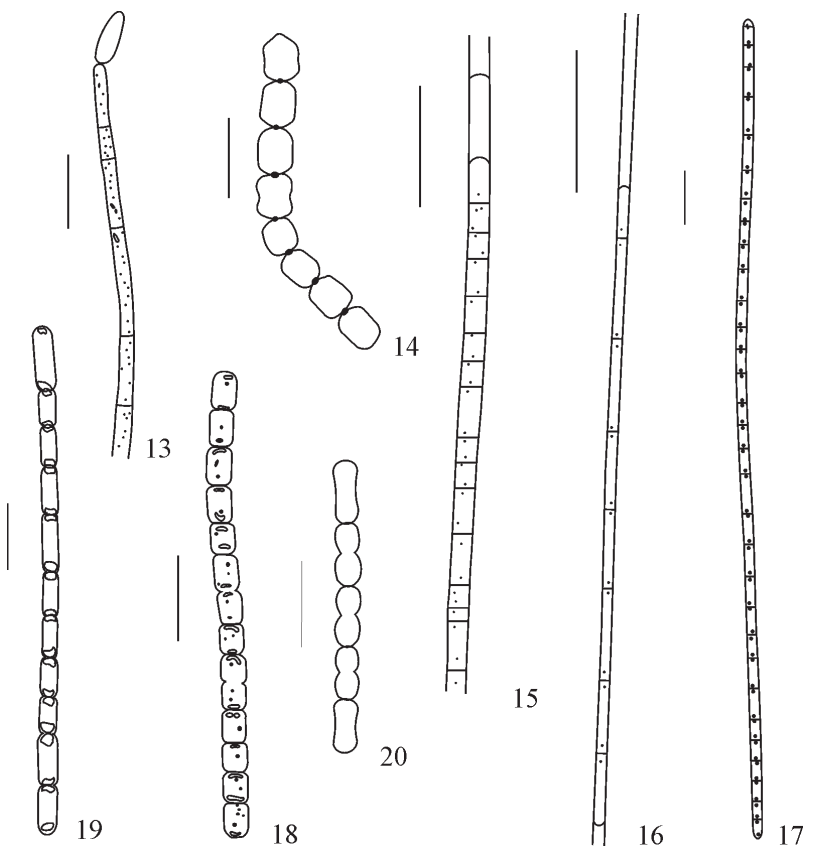

Figure 13. Cylindrospermopsis raciborskii. 14. Komvophoron minutum. 15. Planktolyngbya limnetica. 16. P. minor. 17. Geitlerinema unigranulatum. 18. Limnothrix bicudoi. 19. L. redekei. 20. Pseudanabaena moniliformis. Scale bars: $10 \mu \mathrm{m}$.
Dictyosphaerium pulchellum H.C. Wood, Smithson.

Contrib. Knowl. 19(3): 84. 1873.

Figure 22

Colonies rounded, groups of 4 cells, united by mucilaginous stalks; cells spherical, (6.2-)6.8-9.2(-9.6) $\mu \mathrm{m}$ diam.; chloroplast cup shaped, with one pyrenoid.

Herbarium specimens: BRAZIL. EspíRIto SANTO: Cariacica, Duas Bocas Reservoir, surface, 15-VII-1998, A. Delazari-Barroso s.n. (SP356189).

Chlorellaceae

Chlorella vulgaris Beijerinck, Bot. Ztg. 48: 758. 1890. Figure 23

Cells solitary, spherical, 4.3-7.6 $\mu \mathrm{m}$ diam.; chloroplast cup shaped, with one pyrenoid.

Herbarium specimens: BRAZIL. EsPíRIto SANTO: Cariacica, Duas Bocas Reservoir, surface, 15-VII-1998, A. Delazari-Barroso s.n. (SP356189).

Ankistrodesmus bernardii Komárek, Nova Hedwigia 37: 176. 1983.

Figure 26

Colonies of 8 fusiform-elongated cells, united by center of colony, 22.9-28.5 $\mu \mathrm{m}$ long, 1.1-1.2 $\mu \mathrm{m}$ wide; parietal chloroplast, without pyrenoid.

Herbarium specimens: BRAZIL. EspíRIto SAnto: Cariacica, Duas Bocas Reservoir, surface, 15-VII-1998, A. Delazari-Barroso s.n. (SP356189).

Ankistrodesmus bibraianus (Reinsch) Korshikov, Protococcineae 302. 1953. Selenastrum bibraianum Reinsch, Algenfl. Franken 64. 1867. Figure 25

Colonies of 4-16 cells, convex side oriented to the center of colony; cells lunated or semicircular, gradually narrowing to the apex, 4.3-5.0 $\mu \mathrm{m}$ diam., 8.1-11.2 $\mu \mathrm{m}$ distance between apices; parietal chloroplast, without pyrenoid.

Herbarium specimens: BRAZIL. Espírito Santo: Cariacica, Duas Bocas Reservoir, surface, 22-VII-1998, A. Delazari-Barroso s.n. (SP356191).

Ankistrodesmus fusiformis Corda sensu Korshikov, Protococcineae 300. 1953.

Figure 24 
Colonies star shaped, several straight to fusiformelongated cells, arranged in cross, 25.4-28.5 $\mu \mathrm{m}$ long, 0.6-0.9 $\mu \mathrm{m}$ wide; parietal chloroplast, without pyrenoid.

Herbarium specimens: BRAZIL. EspíRITo SANTO: Cariacica, Duas Bocas Reservoir, surface, 22-VII-1998, A. Delazari-Barroso s.n. (SP356191).

Ankistrodesmus gracilis (Reinsch) Korshikov, Protococcineae 305. 1953. Selenastrum gracile Reinsch, Algenfl. Franken 64.1867.

Figure 27

Colonies of 4 cells, convex side oriented to the center of colony; cells lunated, gradually narrowing to the apex, 3.7-4.6 $\mu \mathrm{m}$ diam., 11.5-13.5 $\mu \mathrm{m}$ distance between apices; parietal chloroplast, without pyrenoid.

Herbarium specimens: BRAZIL. EspíRITo SANTO: Cariacica, Duas Bocas Reservoir, surface, 22-VII-1998, A. Delazari-Barroso s.n. (SP356191).

Kirchneriella dianae var. major (Korshikov) Comas, Acta Bot. Cubana 2: 6. 1980. Kirchneriella intermedia var. major Korshikov, Protococcineae 316. 1953.

\section{Figure 28}

Colonies rounded, inconspicuous mucilage, 4-16 lunate to ovoid cells, apices acuminate, median incision in "U", 8.3-9.5 $\mu \mathrm{m}$ diam., (4.4)5.1-5.5 $\mu \mathrm{m}$ width; parietal chloroplast, with one pyrenoid.

Herbarium specimens: BRAZIL. EspíRITo SANTO: Cariacica, Duas Bocas Reservoir, surface, 15-VII-1998, A. Delazari-Barroso s.n. (SP356189).

Monoraphidium arcuatum (Korshikov) Hindák, Algol. Stud. 1:25. 1970. Ankistrodesmus arcuatus Korshikov, Protococcineae 296. 1953.

Figure 29

Cells solitary, arcuated, apices acuminate, 1.9-3.7 $\mu \mathrm{m}$ diam., 23.9-27.9 $\mu \mathrm{m}$ distance between apices; parietal chloroplast, without pyrenoid.

Herbarium specimens: BRAZIL. EspíRIto SANTO: Cariacica, Duas Bocas Reservoir, surface, 22-VII-1998, A. Delazari-Barroso s.n. (SP356191).

Monoraphidium contortum (Thur.) Komárk.-Legn.,

Studies in Phycol.:104. 1969. Ankistrodesmus contortus Thur., in Brébisson, Mém. Soc. imper. Sci. nat. Cherbourg 4: 158. 1856.

Figure 30
Cells solitary, fusiform-elongated, helicoidal, 1.2-1.4 $\mu \mathrm{m}$ diam., 13.0-33.5 $\mu \mathrm{m}$ distance between apices; parietal chloroplast, without pyrenoid.

Herbarium specimens: BRAZIL. EspíRITO SANTO: Cariacica, Duas Bocas Reservoir, surface, 15-VII-1998, A. Delazari-Barroso s.n. (SP356189).

Monoraphidium griffithii (Berk.) Komárk.-Legn., Stud. Phycol. 89. 1969. Closterium griffithii Berk., Ann. Mag. Nat. Hist. 13, sér. 2: 256. 1854.

Figure 31

Cells solitary, fusiform-elongated, straight, 65.8-69.8 $\mu \mathrm{m}$ long, 1.7-2.0 $\mu \mathrm{m}$ diam.; parietal chloroplast, without pyrenoid.

Herbarium specimens: BRAZIL. Espírito SANTO: Cariacica, Duas Bocas Reservoir, surface, 15-VII-1998, A. Delazari-Barroso s.n. (SP356189).

Monoraphidium minutum (Nägeli) Komárk.-Legn., Stud. Phycol. 109. 1969. Raphidium minutum Nägeli, Gatt. einzell. Alg. 83. 1849.

Figure 32

Cells solitary, lunated, rounded apices, $4.3 \mu \mathrm{m}$ diam., $13.0 \mu \mathrm{m}$ distance between apices; parietal chloroplast, without pyrenoid.

Herbarium specimens: BRAZIL. Espírito SANTO: Cariacica, Duas Bocas Reservoir, surface, 15-VII-1998, A. Delazari-Barroso s.n. (SP356189).

\section{Coelastraceae}

Coelastrum proboscideum Nägeli, Bih. K. Svenska Vetensk Akad. Handl. 23: 33. 1897.

Figure 33

Cenobia quadrangular, triangular or tetrahedrical, intercelular spaces, 4-16 cells almost triangular in lateral view, outer pole with thickness, 3 interconnecting process, each uniting with a neighboring cell, 4.3-4.5 $\mu \mathrm{m}$ long, 6.2-6.5 $\mu \mathrm{m}$ wide; parietal chloroplast, with one pyrenoid.

Herbarium specimens: BRAZIL. EsPíRIto SANTO: Cariacica, Duas Bocas Reservoir, surface, 15-VII-1998, A. Delazari-Barroso s.n. (SP356189).

Coelastrum pulchrum Schmidle, Ber. Dtsch. Bot. Ges. 10: 206. 1892.

Figure 34 
Cenobia sphaerical, intercelular spaces, 8-32 spherical-ovate cells, outer pole with conical-truncate projection, 5-6 interconnecting process, each uniting with a neighboring cell, $70.4 \mu \mathrm{m}$ cenobia diameter, (16.8-)17.4-18.4(-19.1) $\mu \mathrm{m}$ cells diameter, parietal chloroplast, with one pyrenoid.

Herbarium specimens: BRAZIL. Espírito SANTo: Cariacica, Duas Bocas Reservoir, surface, 15-VII-1998, A. Delazari-Barroso s.n. (SP356189).

Hydrodictyaceae

Pediastrum tetras (Ehrenb.) Ralfs, Ann. Mag. nat.

Hist. 14: 469. 1844. Micrasterias tetras Ehrenb., Infusionsthierchen: 155, pl. XI: fig. I. 1838.

Figure 35

Cenobia rounded or quadratic, 4-8-16 cells, arranged concentrically, inner cells with 4-6 sides and a linear incision, outer cells with two bifurcate processes, 10.9-11.9 $\mu \mathrm{m}$ long, 9.9-12.4 $\mu \mathrm{m}$ wide, parietal chloroplast, with one pyrenoid.

Herbarium specimens: BRAZIL. Espírito SANTO: Cariacica, Duas Bocas Reservoir, surface, 15-VII-1998, A. Delazari-Barroso s.n. (SP356189).

\section{Micractiniaceae}

Golenkinia radiata Chodat, J. Bot. 8: 305. 1894. Figure 36

Cells solitary, spherical, 6.4-9.4 $\mu \mathrm{m}$ diam.; cell wall with numerous straight spines arranged irregularly, 8.1-10.5 $\mu \mathrm{m}$ long; chloroplast cup shaped, with one pyrenoid.

Herbarium specimens: BRAZIL. Espírito SANTo: Cariacica, Duas Bocas Reservoir, surface, 15-VII-1998, A. Delazari-Barroso s.n. (SP356189).

Scenedesmaceae

Tetrallantos lagerheimii Teiling, Svensk. vot. Tidskr. 10: 62. 1916.

Figure 37

Cenobia of 4 lunate cells, rounded apices, cells in 2 pair, 1 pair facing each other and in contact at their poles, the other pair vertical to these, $14.3-16.2 \mu \mathrm{m}$ long, 5.0-5.3 $\mu \mathrm{m}$ wide; parietal chloroplast, with one pyrenoid.

Herbarium specimens: BRAZIL. EsPíRITO SANTO: Cariacica, Duas Bocas Reservoir, surface, 15-VII-1998, A. Delazari-Barroso s.n. (SP356189).
Didymocystis fina Komárek, Preslia 47: 276. 1975. Figure 38

Cenobia of two parallel cells, oblongs, cell wall smooth, 4.3-5.0 $\mu \mathrm{m}$ long, 2.0-2.2 $\mu \mathrm{m}$ wide; parietal chloroplast, with one pyrenoid.

Herbarium specimens: BRAZIL. EsPíRIto SANTO: Cariacica, Duas Bocas Reservoir, surface, 15-VII-1998, A. Delazari-Barroso s.n. (SP356189).

Didymocystis inermis (Fott) Fott, Preslia 45: 6. 1973. Dicelulla inermis Fott, Stub. Bot. Cech. 4:64. 1941. Figure 39

Cenobia of two parallel cells, oblongs, cell wall with granules, 7.3-8.0 $\mu \mathrm{m}$ long, 3.8-4.6 $\mu \mathrm{m}$ wide; parietal chloroplast, without pyrenoid.

Herbarium specimens: BRAZIL. Espírito SAnto: Cariacica, Duas Bocas Reservoir, surface, 15-VII-1998, A. Delazari-Barroso s.n. (SP356189).

Scenedesmus acuminatus (Lagerh.) Chodat, Beitr.

Kryptogamen F1. Schweiz 1(3): 211. 1902.

Selenastrum acuminatum Lagerh., Ofvers. K.

VetenskAkad. Förh. 39(2):71.1882.

Figure 40

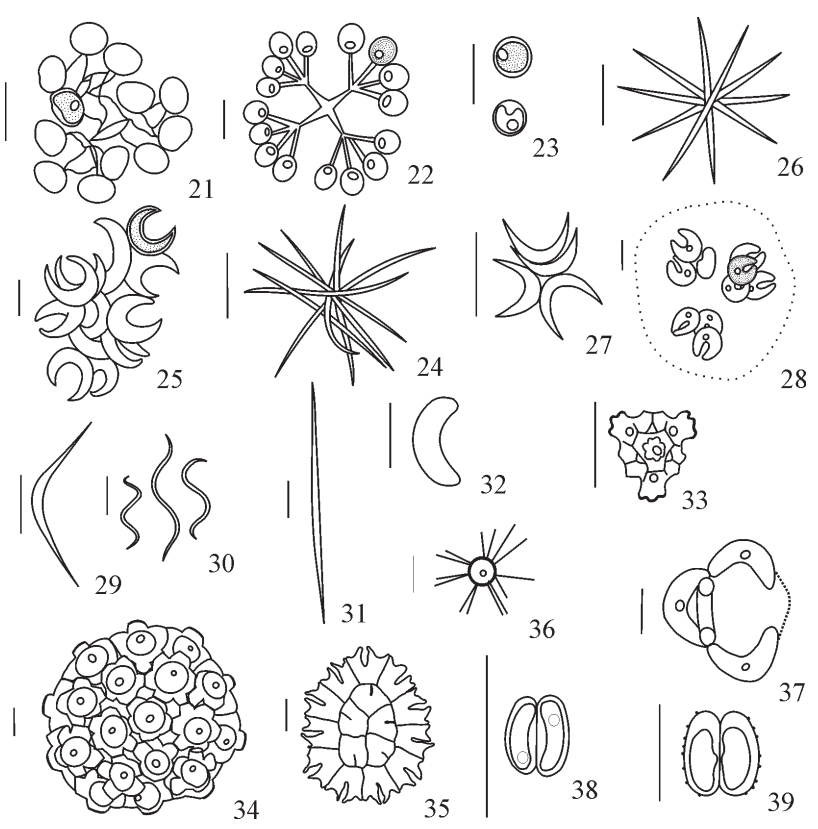

Figure 21. Dictyosphaerium ehrenbergianum. 22. D. pulchellum. 23. Chlorella vulgaris. 24. Ankistrodesmus fusiformis. 25. A. bibraianus. 26. A. bernardii. 27. A. gracilis. 28. Kirchneriella dianae var. major. 29. Monoraphidium arcuatum. 30. M. contortum. 31. M. griffithii. 32. M. minutum. 33. Coelastrum proboscideum. 34. C. pulchrum. 35. Pediastrum tetras. 36. Golenkinia radiata. 37. Tetrallantos lagerheimii. 38. Didymocystis fina. 39. D. inermis. Scale bars: $10 \mu \mathrm{m}$. 
Cenobia of 4-8 cells linear or alternately arranged; cells lunate, arcuate, apices acuminate, 18.4-26.2 $\mu \mathrm{m}$ long, 3.0-7.3 $\mu \mathrm{m}$ wide; parietal chloroplast, with one pyrenoid.

Herbarium specimens: BRAZIL. Espírito SAnto: Cariacica, Duas Bocas Reservoir, surface, 22-VII-1998, A. Delazari-Barroso s.n. (SP356191).

Desmodesmus armatus var. bicaudatus (Gugl.) E. Hegewald, Arch. Hydrobiol. Suppl. 131 (Algol. Stud. 96): 4. 2000. Scenedesmus bicaudatus (Hansgirg) Chodat, Z. Hydrol. 3: 248. 1926.

Figure 41

Cenobia of 2-4 cells linearly arranged; cells oblong-elliptics, $13.0 \mu \mathrm{m}$ long, 4.9-5.0 $\mu \mathrm{m}$ wide; outer cells with one spine on one of the poles, diagonally arranged; parietal chloroplast, with one pyrenoid.

Herbarium specimens: BRAZIL. EspíRIto SANTo: Cariacica, Duas Bocas Reservoir, surface, 22-VII-1998, A. Delazari-Barroso s.n. (SP356191).

Scenedesmus disciformis (Chodat) Fott \& Komárek., Preslia 32: 129. 1960. Scenedesmus bijugatus var. disciformis R. Chod., Alg. Vert. Suisse. 213. 1902. Figure 42

Cenobia of 8 cells arranged in two superimposed series; cells oblong, compressed by mutual pressure, 8.9-10.0 $\mu \mathrm{m}$ long, 5.1-6.1 $\mu \mathrm{m}$ wide; parietal chloroplast, with one pyrenoid.

Herbarium specimens: BRAZIL. Espírito SAnto: Cariacica, Duas Bocas Reservoir, surface, 22-VII-1998, A. Delazari-Barroso s.n. (SP356191).

Scenedesmus ecornis (Ehrenb.) Chodat, Z. Hidrol.

3: 170. 1926. Scenedesmus quadricauda var. ecornis Ehrenb. ex Ralfs.

Figures 43-44

Cenobia of 2-4 cells linearly arranged; cells oblong-elliptics, 6.8-13.5(-18.4) $\mu \mathrm{m}$ long, 3.3-4.6(-8.9) $\mu \mathrm{m}$ wide; outer cells with one spine on one of the poles, diagonally arranged; parietal chloroplast, with one pyrenoid.

Herbarium specimens: BRAZIL. Espírito SAnto: Cariacica, Duas Bocas Reservoir, surface, 22-VII-1998, A. Delazari-Barroso s.n. (SP356191).
Desmodesmus perforatus (Lemmerm.) E. Hegewald, Arch. Hydrobiol. Suppl. 131 (Algol. Stud. 96): 15. 2000. Scenedesmus perforatus Lemmerm., Z. Fisch. 11: 104. 1903.

Figure 45

Cenobia clathrate of 4-8 cells linearly arranged; cells cylindrical, outer margin convex and inner margin concave, 14.6-16.7 $\mu \mathrm{m}$ long, 5.2-6.7 $\mu \mathrm{m}$ wide, outer cells with one curved spine on each pole; parietal chloroplast, with one pyrenoid.

Herbarium specimens: BRAZIL. EsPíRIto SANTO: Cariacica, Duas Bocas Reservoir, surface, 22-VII-1998, A. Delazari-Barroso s.n. (SP356191).

Scenedesmus quadricauda (Turpin) Brébrisson, in Brebisson \& Godey, Mém. Soc. Acad. Falaise 1835: 66. 1835. Achanthes quadricauda Turpin, Mém. Mus. Hist. Nat. 16: 311.1828.

Figures 46-47

Cenobia of 4-8 cells linearly arranged; cells oblong-elliptics, 8.4-10.2 $\mu \mathrm{m}$ long, 3.5-4.3 $\mu \mathrm{m}$ wide, outer cells with one spine on each pole; parietal chloroplast, with one pyrenoid.

Herbarium specimens: BRAZIL. EsPíRIto SANTO: Cariacica, Duas Bocas Reservoir, surface, 22-VII-1998, A. Delazari-Barroso s.n. (SP356191).

Scenedesmus cf. semipulcher Hortob., Nova Hedwigia 1:359. 1960.

Figure 48

Cenobia of 4 cells linearly arranged; cells oblongelliptics, (11.2-)12.1-15.5(-17.2) $\mu \mathrm{m}$ long, 2.8-5.3(-6.1) $\mu \mathrm{m}$ wide, outer cells with one spine on one of the poles, diagonally arranged, inner cells with one short spine on each pole; parietal chloroplast, with one pyrenoid.

Herbarium specimens: BRAZIL. Espírito SAnto: Cariacica, Duas Bocas Reservoir, surface, 22-VII-1998, A. Delazari-Barroso s.n. (SP356191).

Comments: the studied population differs from the typical form by lacking longitudinal ribs.

Desmodesmus spinosus (Chodat) E. Hegewald, Arch. Hydrobiol. Suppl. 131 (Algol. Stud. 96): 17. 2000. Scenedesmus spinosus Chodat, Monogr. Alg. Cult. Pure: 74.1913.

Figure 49 
Cenobia of 4 cells linearly arranged; cells oblong with slightly conical poles, 10.6-11.2 $\mu \mathrm{m}$ long, 2.8-3.1 $\mu \mathrm{m}$ wide, outer cells with convex margin and two long spines, inner cells with short and long spines on the poles, diagonally arranged; parietal chloroplast, with one pyrenoid.

Herbarium specimens: BRAZIL. Espírito SAnto: Cariacica, Duas Bocas Reservoir, surface, 22-VII-1998, A. Delazari-Barroso s.n. (SP356191).

\section{VOLVOCALES}

Chlamydomonadaceae

Chlamydomonas pseudotarda Bourrelly, Hydrobiol. 3: 17. 1951.

Figure 50

Cells solitary, oblong or elliptic, anterior papilla, two apical flagella, (15.3-)16.8-27.5 $\mu \mathrm{m}$ long, (7.7-)8.0-15.0(-17.6) $\mu \mathrm{m}$ wide; chloroplast urceolate, with 5 pyrenoids.

Herbarium specimens: BRAZIL. EsPíRITO SANTO: Cariacica, Duas Bocas Reservoir, surface, 10-III-1999, A. Delazari-Barroso s.n. (SP356195).

\section{CONJUGATOPHYCEAE \\ DESMIDIALES \\ Desmidiaceae}

Actinotaenium perminutum (West) Teil., Folia Geobot. Phytotax. 13: 56. 1978.

Figure 51

Cells guitar-shaped, 1.4 to 1.5 times longer than broad, 8.9-9.3 $\mu \mathrm{m}$ long, $6.1 \mu \mathrm{m}$ wide; sinus very extended and shallow, isthmus 4.3-5.3 $\mu \mathrm{m}$ wide; cell wall smooth or with few puncta; circular in vertical view.

Herbarium specimens: BRAZIL. EspíRIto SAnto: Cariacica, Duas Bocas Reservoir, surface, 5-VIII-1998, A. Delazari-Barroso s.n. (SP356193).

\section{Cosmarium asphaerosporum var. strigosum}

Nordst., in Wittr. \& Nordst., Alg. exsicc. No 1264, Alg. Aquae dulcis: 86. 1897.

Figure 52

Cells 1.2 times longer than broad, $6.8 \mu \mathrm{m}$ long, $5.6 \mu \mathrm{m}$ wide; sinus open, isthmus $2.4 \mu \mathrm{m}$ wide; semicells obovate to elliptical; cell wall smooth; elliptic in vertical view; obovate-subcircular in lateral view.
Herbarium specimens: BRAZIL. Espírito SAnto: Cariacica, Duas Bocas Reservoir, surface, 5-VIII-1998, A. Delazari-Barroso s.n. (SP356193).

Cosmarium cf. capitulum Roy \& Bisset, J. Bot. 24: 195. 1886.

Figure 53

Cells 1.2 to 1.4 times longer than broad, 10.5-13 $\mu \mathrm{m}$ long, 8.1-9.6 $\mu \mathrm{m}$ wide; sinus open, acute, isthmus 4.3-6.1 $\mu \mathrm{m}$ wide; semicells subcircular, apex convex, sometimes twisted, angles slightly mamillated; cell wall smooth; elliptic in vertical view; subcircular in lateral view.

Herbarium specimens: BRAZIL. EspíRIto SANTo: Cariacica, Duas Bocas Reservoir, surface, 5-VIII-1998, A. Delazari-Barroso s.n. (SP356193).

Comments: differs from the typical by cell dimensions, the semicells more stout and the sinus broad and not so deep.

Cosmarium pseudobroomei Wolle, Bull. Torr. Bot. Club 11(2):16. 1884.

Figure 54

Cells about as broad as long, $32.2 \mu \mathrm{m}$ long, $34.1 \mu \mathrm{m}$ wide; sinus deep, narrowly linear isthmus $10.5 \mu \mathrm{m}$ wide; semicells oblong-rectangular, lateral margins slightly convex, apex straight; cell wall densely granular in oblique series; oblong in vertical view; subcircular in lateral view.

Herbarium specimens: BRAZIL. Espírito SAnto: Cariacica, Duas Bocas Reservoir, surface, 29-VII-1998, A. Delazari-Barroso s.n. (SP356192).

Cosmarium pseudoconnatum Nordst., Vidensk. Medd. Naturh. Foren. Kjöbenhavn 1869 (14-15): 214. 1870.

Figure 55

Cells 1.3 times longer than broad, 39.7-42.2 $\mu \mathrm{m}$ long, 31.9-34.1 $\mu \mathrm{m}$ wide; sinus very broad and shallow, isthmus 30.6-33 $\mu \mathrm{m}$ wide; semicells semicircular, chloroplasts parietal, four in each semicell; cell wall smooth; circular in vertical view; in lateral view the same shape as in front view.

Herbarium specimens: BRAZIL. Espírito SAnto: Cariacica, Duas Bocas Reservoir, surface, 15-VII-1998, A. Delazari-Barroso s.n. (SP356189). 
Teilingia granulata (J. Roy \& Bisset) Bourrelly ex Compère, Revue Algol. 7: 190. 1964. Sphaerozosma granulatum J. Roy \& Bisset, J. Bot. 24: 242. 1886.

\section{Figure 56}

Cells about as broad as long, 6.1-7.4 $\mu \mathrm{m}$ long, 5.6-6.8 $\mu$ m wide; sinus widely open, isthmus $2.8-4 \mu \mathrm{m}$ wide; semicells oblong, lateral and apical margins with small marginal and intramarginal granules; subcircular in lateral view; angularly oblong in vertical view.

Herbarium specimens: BRAZIL. EspíRIto SANTO: Cariacica, Duas Bocas Reservoir, surface, 5-VIII-1998, A. Delazari-Barroso s.n. (SP356193).

Staurastrum excavatum West \& West, Trans. Linn.

Soc. London 5: 78. 1845.

Figure 57

Cells 1.3 to 1.4 times longer than broad without processes, 11.2-11.8 $\mu \mathrm{m}$ long, 8.1-8.7 $\mu \mathrm{m}$ wide; 28.5-37.8 $\mu \mathrm{m}$ long, 43.4-50.5 $\mu \mathrm{m}$ wide with processes; sinus acute, open, isthmus 5.3-5.6 $\mu \mathrm{m}$ wide; semicells campanulate, apical processes long, undulate, and tipped with three spines; birradiate ion vertical view.

Herbarium specimens: BRAZIL. EsPíRITo SANTO: Cariacica, Duas Bocas Reservoir, surface, 15-VII-1998, A. Delazari-Barroso s.n. (SP356189).

Staurastrum forficulatum var. minus (F.E. Fritsch \& M.F. Rich) R.L. Grönblad \& A.M. Scott, Acta Bot. Fenn. 58: 40.1958. Staurastrum furcatum f. minor F.E. Fristsch \& M.F. Rich, Trans. Roy. Soc. S. Afr. 25: 205. 1937.

Figure 58

Cells 1.2 to 1.4 times longer than broad without processes, 15.2-19.8 $\mu \mathrm{m}$ long, 12.4-14.6 $\mu \mathrm{m}$ wide; 16.7-19.8 $\mu \mathrm{m}$ long, 16.4-24.8 $\mu \mathrm{m}$ wide with processes; sinus open, acute, isthmus 5.6-7.4 $\mu \mathrm{m}$ wide; semicells subtrapeziform, upper margin with stout spines, lateral angles with two bifid, stout and diverging spines; vertical view triangular, angles with two superimposed spines, two intramarginal processes on each side.

Herbarium specimens: BRAZIL. EspíRIto SANTo: Cariacica, Duas Bocas Reservoir, surface, 15-VII-1998, A. Delazari-Barroso s.n. (SP356189).

Staurastrum laeve Ralfs, in The British Desmidiaceae: 131. 1848.

Figure 59

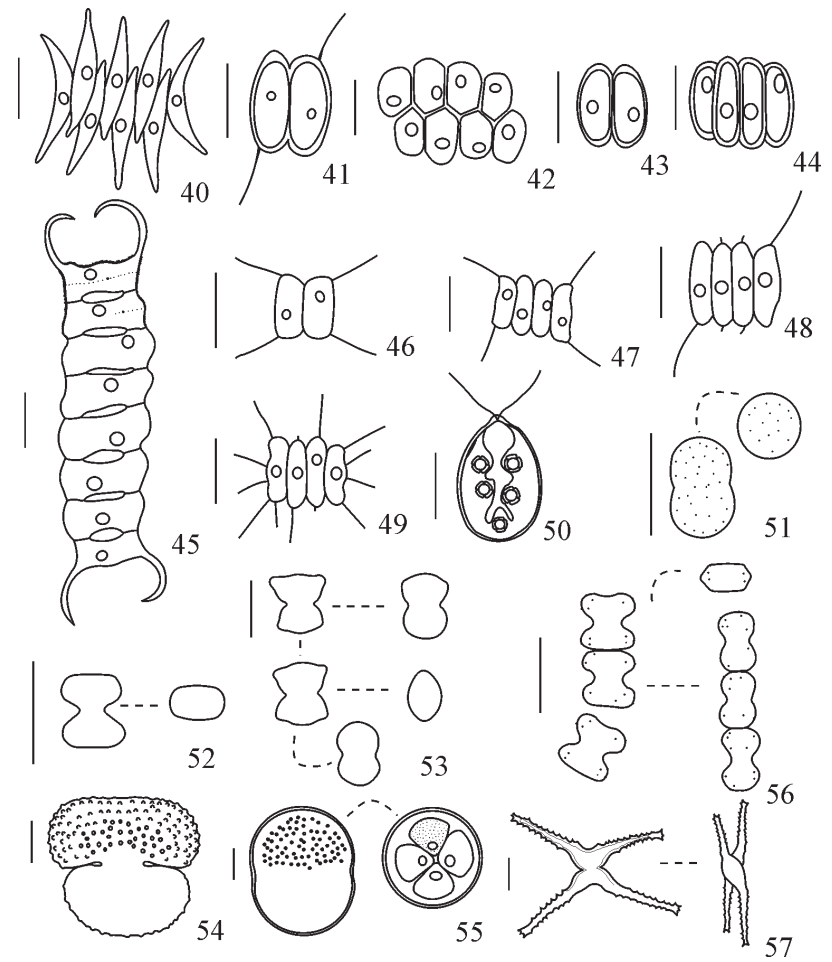

Figure 40. Scenedesmus acuminatus. 41. Desmodesmus armatus var. bicaudatus. 42. Scenedesmus disciformis. 43-44. Scenedesmus ecornis. 45. Desmodesmus perforatus. 46-47. Scenedesmus quadricauda. 48. Scenedesmus cf. semipulcher. 49. Desmodesmus spinosus. 50. Chlamydomonas pseudotarda. 51. Actinotaenium perminutum. 52. Cosmarium asphaerosporum var. strigosum. 53. C. cf. capitulum. 54. C. pseudobroomei. 55. C. pseudoconnatum. 56. Teilingia granulata. 57. Staurastrum excavatum. Scale bars: $10 \mu \mathrm{m}$.

Cells 1.5 times longer than broad without processes, 15.5-17 $\mu \mathrm{m}$ long, 10.1-15.2 $\mu \mathrm{m}$ wide; 16.4-19.7 $\mu \mathrm{m}$ long, 14-18.7 $\mu \mathrm{m}$ wide with processes; sinus open, acute, isthmus 5.3-6.9 $\mu$ m wide; semicells subtriangular, apex slightly convex, angles slightly produced to form short, stout and bifurcate processes; cell wall smooth; triangular in vertical view, margins straight between stout, bifurcate processes.

Herbarium specimens: BRAZIL. EsPíRIto SANTO: Cariacica, Duas Bocas Reservoir, surface, 15-VII-1998, A. Delazari-Barroso s.n. (S356189).

Staurastrum margaritaceum (Ehrenb.) Ralfs, in The British Desmidiaceae: 134. 1848. Pentasterias margaritaceae Ehrenb., Infus.144.1838.

Figure 60

Cells 1.6 to 1.9 times longer than broad without processes, 16.7-19.8 $\mu \mathrm{m}$ long, $10.5 \mu \mathrm{m}$ wide; 22.3-25.4 $\mu \mathrm{m}$ wide with processes; sinus open with 
an open notch, isthmus $5.9 \mu \mathrm{m}$ wide; semicells cupshaped, apex with lateral arms horizontally directed, apical margin convex; cell wall with vertical series of granules; vertical view with five arms, margins concave.

Herbarium specimens: BRAZIL. EspíRIto SANTO: Cariacica, Duas Bocas Reservoir, surface, 5-VIII-1998, A. Delazari-Barroso s.n. (SP356193).

Staurastrum micron W.West \& G.S.West, Brit. Desm. 5: 123. 1923.

\section{Figure 61}

Cells 1.2 to 1.6 times longer than broad without processes, 9.4-11.2 $\mu \mathrm{m}$ long, 6.3-8.7 $\mu \mathrm{m}$ wide; 14.8-17.4 $\mu \mathrm{m}$ long, 16.1-20.5 $\mu \mathrm{m}$ wide with processes; sinus open, isthmus 3.6-4.0 $\mu \mathrm{m}$ wide; semicells subtriangular, angles produced to form relatively short, upturned processes with marginal spines, bearing three teeth at the apex, apical margin truncate with small spines; vertical view triangular, margins concave between short processes with marginal spines.

Herbarium specimens: BRAZIL. Espírito SANTO: Cariacica, Duas Bocas Reservoir, surface, 15-VII-1998, A. Delazari-Barroso s.n. (SP356189).

Staurastrum quadrangulare var. armatum W.West \& G.S.West, Trans. Linn. Soc. London 2:257. 1896. Figure 62

Cells 1.1 to 1.6 times longer than broad without processes, 12.4-13.5 $\mu \mathrm{m}$ long, 8.1-11.8 $\mu \mathrm{m}$ wide; 13.8-18.6 $\mu \mathrm{m}$ long, $13-15.5 \mu \mathrm{m}$ wide with processes; sinus open, isthmus 4.9-5.9 $\mu \mathrm{m}$ wide; semicells subrectangular, lateral angles rounded, with two bifid, diverging spines; apical margin flat; cell wall punctate; triangular in vertical view, margins concave, angles with two marginal spines.

Herbarium specimens: BRAZIL. EsPíRITO SANTO: Cariacica, Duas Bocas Reservoir, surface, 15-VII-1998, A. Delazari-Barroso s.n. (SP356189).

Staurastrum rotula Nordstedt., Vidnsk. Medd. Naturh. Foren. Kjöbenhavn 1869: 227. 1870. Figure 63

Cells 1.8 to 1.9 times longer than broad without processes, 31-35.2 $\mu \mathrm{m}$ long, 16.1-18.4 $\mu \mathrm{m}$ wide; 40.9-44.4 $\mu \mathrm{m}$ wide with processes; sinus open, rounded, isthmus $8.4 \mu \mathrm{m}$ wide; semicells subhexagonal, apical angles forming relatively long processes tipped with three teeth, margins with small spines, apical margin slightly convex with a intramarginal series of warts; cell wall granular; six-rayed in vertical view, margins deeply concave between processes, midregion with a circular series of warts.

Herbarium specimens: BRAZIL. EsPíRIto SANTO: Cariacica, Duas Bocas Reservoir, surface, 22-VII-1998, A. Delazari-Barroso s.n. (SP356191).

Staurastrum smithii (G.M. Smith) Teiling, Bot. Notiser 1946: 82. 1946. Staurastrum contortum G.M. Smith, Wisc. Geol. nat. Hist. Surv. Bull. 57(2): 98.1924

Figure 64

Cells 1 to 1.7 times longer than broad without processes, 8.2-10.5 $\mu \mathrm{m}$ long, 5.6-8.1 $\mu \mathrm{m}$ wide; 14.9-22.6 $\mu \mathrm{m}$ long, 29.1-36 $\mu \mathrm{m}$ wide with processes; sinus widely open, $\mathrm{U}$-shaped, isthmus 3.4-5.2 $\mu \mathrm{m}$ wide; semicells conversely triangular, sometimes twisted, apical angles produced to form long, slightly diverging arms with spiny margins, tipped with three teeth, apical margin slightly concave; elliptic to fusiform in vertical view, birradiate.

Herbarium specimens: BRAZIL. EspíRIto SAnto: Cariacica, Duas Bocas Reservoir, surface, 15-VII-1998, A. Delazari-Barroso s.n. (SP356189).

Staurastrum tetracerum (Kütz.) Ralfs, Ann. Mag. Nat. Hist., 15: 150. 1845. Micrasterias tetracera Kützing, Linnaea 1833: 602.1833.

Figure 65

Cells 1.5 to 1.7 times longer than broad without processes, $7.4 \mu \mathrm{m}$ long, 4.4-5 $\mu \mathrm{m}$ wide; $20.1-25.1 \mu \mathrm{m}$ long, 22.9-26 $\mu \mathrm{m}$ wide with processes; sinus open, V-shaped, isthmus 3.7-4 $\mu \mathrm{m}$ wide; semicells subtriangular to cuneate, apical angles forming upward, diverging processes, margins serrulate, tipped with two-three teeth, apical margin concave; birradiate in vertical view.

Herbarium specimens: BRAZIL. EsPíRIto SANTO: Cariacica, Duas Bocas Reservoir, surface, 15-VII-1998, A. Delazari-Barroso s.n. (SP356189).

Staurodesmus controversus (W. West \& G.S. West) Teiling, Ark. Bot. 6: 504. 1967. Arthrodesmus controversus W. West \& G.S. West, J. Roy. Micr. Soc. 1894: 9.1894.

Figure 66 
Cells about as broad as long, 9.9-10.8 $\mu \mathrm{m}$ long, 9.6-10.5 $\mu \mathrm{m}$ wide; sinus acute, widely open, isthmus 5.6-6.5 $\mu \mathrm{m}$ wide; semicells almost square-shaped, slightly convex, angles with a short spine; elliptic to oval in vertical view.

Herbarium specimens: BRAZIL. EspíRIto SANTO: Cariacica, Duas Bocas Reservoir, surface, 22-VII-1998, A. Delazari-Barroso s.n. (SP356191).

Staurodesmus cf. crassus (W. West \& G.S. West) Florin, Acta Phytogeogr. Suec. 37: 138. 1957. Arthrodesmus crassus W. West \& G.S. West, J.Linn.Soc. 35: 541.1903.

Figure 69

Cells 1.4 to 1.6 times longer than broad without spines, 9.3-11.2 $\mu \mathrm{m}$ long, 6.2-8.1 $\mu \mathrm{m}$ wide; 12.1-13.5 $\mu \mathrm{m}$ long, 7.4-9.9 $\mu \mathrm{m}$ wide with spines; sinus open, acute, isthmus 3.7-4.7 $\mu \mathrm{m}$ wide; semicells subtriangular, often twisted, acute angles with a short spine; elliptic in vertical view.

Herbarium specimens: BRAZIL. EspíRITo SANTO: Cariacica, Duas Bocas Reservoir, surface, 15-VII-1998, A. Delazari-Barroso s.n. (SP356189).

Differs from the typical by smaller cell dimensions, apical margin concave and spines more thin, divergent.

Staurodesmus dejectus (Brébisson ex Ralfs) Teiling, Rapp. VIII Congr. Int. Bot. 7: 128. 1954. Staurastrum dejectum Brébisson ex Ralfs, The British Desmidieae 121. 1848.

Figure 67

Cells 1.2 times longer than broad, 16.4-18.1 $\mu \mathrm{m}$ long, 15.5-19.2 $\mu \mathrm{m}$ wide; sinus open, rounded, isthmus 4-4.9 $\mu \mathrm{m}$ wide; semicells cup-shaped, apical margin convex, angles with short spine, divergent; triangular in vertical view.

Herbarium specimens: BRAZIL. EspíRIto SANTo: Cariacica, Duas Bocas Reservoir, surface, 15-VII-1998, A. Delazari-Barroso s.n. (SP356189).

Staurodesmus indentatus (W. West) Teiling var. rectangularis (Scott \& Grönblad) Teiling, Arch. Botanik, 6: 522. 1967. Arthrodesmus triangularis var. rectangularis Scott \& Grönblad, Acta Soc. Sc. Fenn. 2(8): 29.1957.

Figure 68

Cells 1.3 times longer than broad without spines,
$16.5 \mu \mathrm{m}$ long, $12.2 \mu \mathrm{m}$ wide; $33.6 \mu \mathrm{m}$ wide with spines; sinus widely open, isthmus $3.5 \mu \mathrm{m}$ wide; semicells subtriangular to cup-shaped, apical margin slightly convex, spines long, convergent or rarely parallel; elliptic in vertical view.

Herbarium specimens: BRAZIL. EsPíRIto SANTO: Cariacica, Duas Bocas Reservoir, surface, 10-III-1999, A. Delazari-Barroso s.n. (SP356195).

Xanthidium cf. smithii W. Archer, Bot. Notiser 52: 159. 1887.

Figure 70

Cells about as broad as long without spines, 9.3-10.5 $\mu \mathrm{m}$ long, 8.7-11.2 $\mu \mathrm{m}$ wide; 11.8-14.6 $\mu \mathrm{m}$ long, 11.2-16.1 $\mu \mathrm{m}$ wide with spines; sinus deep, acute, isthmus 2.5-3.1 $\mu \mathrm{m}$; semicells hexagonal, lateral and apical angles with one short spine; cell wall smooth; angularly oval in vertical view, the poles truncate and furnished with one spine at each angle.

Herbarium specimens: BRAZIL. Espírito Santo: Cariacica, Duas Bocas Reservoir, surface, 15-VII-1998, A. Delazari-Barroso s.n. (SP356189).

Differs from the typical by smaller cell dimensions, the shape of the semicell (hexagonal instead of truncate-pyramidal), the spines more thin and the midregion of the semicell that is smooth.

\section{EUGLENOPHYCEAE \\ EUGLENALES}

Euglenaceae

Euglena limnophila Lemmerm., Botanisches Centralblatt, 76: 152.1898.

Figure 71

Cells fusiform, $55.8 \mu \mathrm{m}$ long, $12.4 \mu \mathrm{m}$ diam., posterior end attenuated in a conical caudal process; pellicule with faint helicoidal stripes; numerous discoid chloroplasts, two paramylon grains; stigma small.

Herbarium specimens: BRAZIL. Espírito SANTO: Cariacica, Duas Bocas Reservoir, surface, 15-VII-1998, A. Delazari-Barroso s.n. (SP356189).

Lepocinclis ovum (Ehrenb.) Lemmerm., Ber. Dtsch.Bot.Ges.19:88.1901. Euglena ovum Ehrenb., Berl. K. Akad. Wiss. Berlin 1840: 200. 1840.

Figure 72

Cells elliptic, $22.4 \mu \mathrm{m}$ long, $11.8 \mu \mathrm{m}$ diam., 


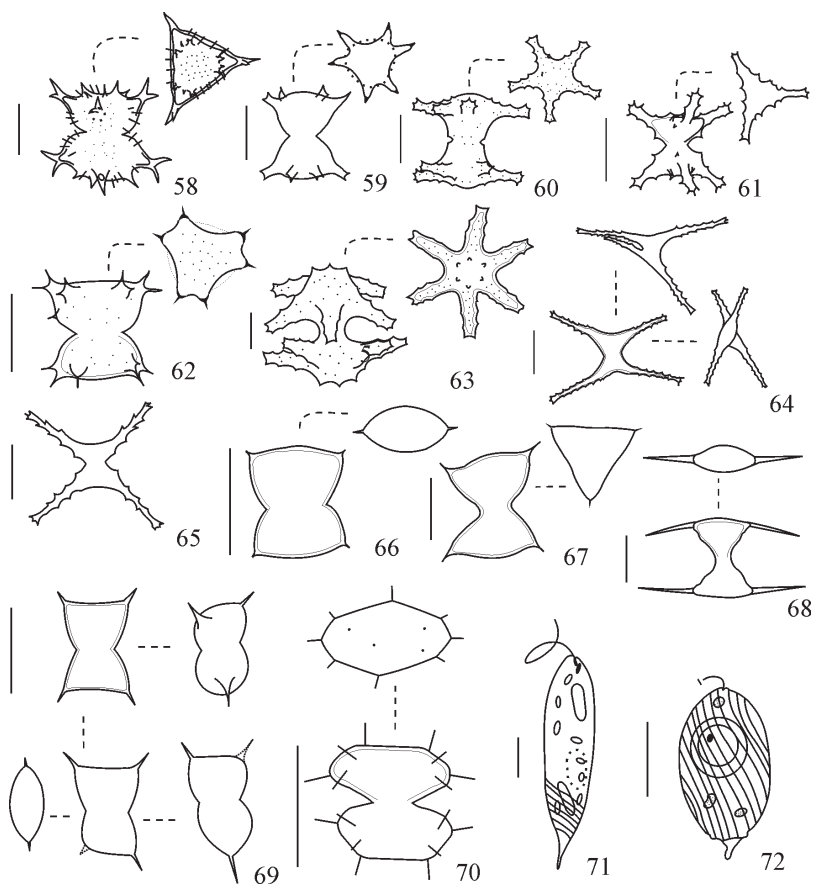

Figure 58. Staurastrum forficulatum var. minus. 59. S. laeve. 60. S. margaritaceum. 61. S. micron. 62. S. quadrangulare var. armatum. 63. S. rotula. 64. S. smithii. 65. S. tetracerum. 66. Staurodesmus controversus. 67. S. dejectus. 68. S. indentatus var. rectangularis. 69. S. cf. crassus. 70. Xanthidium cf. smithii. 71. Euglena limnophila. 72. Lepocinclis ovum. Scale bars: $10 \mu \mathrm{m}$.

posterior end attenuated in a conical caudal process; pellicule with helicoidal stripes; numerous discoid chloroplasts, two annular, lateral paramylon grains; stigma small..

Herbarium specimens: BRAZIL. EspíRIto SAnto: Cariacica, Duas Bocas Reservoir, surface, 15-VII-1998, A. Delazari-Barroso s.n. (SP356189).

Strombomonas ovalis (Playfair) Deflandre, Arch.

Protistenk. 69: 577. 1930. Trachelomonas urceolata var. ovalis Playfair, Proc. Linn. Soc. N.S.W. 40: 31. 1915.

\section{Figure 73}

Lorica oval-large, $56.6 \mu \mathrm{m}$ long, $38.2 \mu \mathrm{m}$ diam., anterior end with a cylindrical collar, posterior end tapered to a conical caudal process; wall smooth; numerous discoid chloroplasts, numerous discoid paramylon grains.

Herbarium specimens: BRAZIL. Espírito SAnto: Cariacica, Duas Bocas Reservoir, surface, 15-VII-1998, A. Delazari-Barroso s.n. (SP356189).
Trachelomonas armata var. steinii Lemmerm., Abh. Naturw. Ver. Bremen 8:165. 1905.

Figure 74

Lorica elliptic, $55.8 \mu \mathrm{m}$ long, $32.9 \mu \mathrm{m}$ diam.; anterior end lacking collar and with small spines; posterior end with straight spines, wall pointed; numerous discoid chloroplasts with pyrenoids, numerous paramylon grains.

Herbarium specimens: BRAZIL. EsPíRIto SANTO: Cariacica, Duas Bocas Reservoir, surface, 15-VII-1998, A. Delazari-Barroso s.n. (SP356189).

Trachelomonas volvocina Ehrenb., Infus. 48: 18. 1938.

Figure 75

Lorica spherical, 9.5-9.9 $\mu \mathrm{m}$ diam., pore with ring thickening; wall smooth; two parietal elongated chloroplasts, each with an inner pyrenoid; stigma small.

Herbarium specimens: BRAZIL. EsPíRIto SANTO: Cariacica, Duas Bocas Reservoir, surface, 15-VII-1998, A. Delazari-Barroso s.n. (SP356189).

\section{DINOPHYCEAE \\ PERIDINIALES}

Peridiniaceae

Peridinium africanum Lemmerm., J. Linn. Soc. Bot.

38: 188. 1907.

Figure 76

Cells pentagonal, 35.7-39.8 $\mu \mathrm{m}$ long, 29-33.5 $\mu \mathrm{m}$ wide; sulcus extending slightly onto epitheca, enlarging on hipotheca, reach the antapex; small teeth or spines on margins of hipotheca or on antapical plates; sutures straight, striated; plate formula: 4', 2a, 7", 5'", 2"'”.

Herbarium specimens: BRAZIL. EsPíRIto SANTo: Cariacica, Duas Bocas Reservoir, surface, 15-VII-1998, A. Delazari-Barroso s.n. (SP356189).

Peridinium gutwinskii Wolosz., Bull. Acad. Sci. Cracovie (B): 58. 912.

Figure 77

Cells irregularly spherical, ovoid or egg-shaped, 45.3-50.8 $\mu \mathrm{m}$ long, 37.8-48.4 $\mu \mathrm{m}$ wide; deep cingulum spiralling left, flanged sulcus widens along the hipotheca, does not reach the antapex; antapical plates strongly concave; plates bear distinct reticulations. 
Herbarium specimens: BRAZIL. EspíRITo SANTO: Cariacica, Duas Bocas Reservoir, surface, 15-VII-1998, A. Delazari-Barroso s.n. (SP356189).

Peridinium umbonatum Stein, Infus. 3(2): 38. 1883. Figure 78

Cells pentagonal, 28.8-39.7 $\mu \mathrm{m}$ long, 28.2-41.3 $\mu \mathrm{m}$ wide; cingulum spiralling left, sulcus extending slightly onto epitheca, enlarging on hipotheca, does not reach the antapex, small teeth or spines on margins of hipotheca, sutures straight, smooth; plate formula: 4', 2a, 7", 5'", 2"'".

Herbarium specimens: BRAZIL. Espírito SANTO: Cariacica, Duas Bocas Reservoir, surface, 15-VII-1998, A. Delazari-Barroso s.n. (SP356189).

\section{CRYPTOPHYCEAE}

CRYPTOMONADALES

Cryptomonadaceae

Cryptomonas parapyrenoidifera Skuja, Symb. Bot. Upsal. 9(3): 352. 1948.

Figure 79

Cells obovate in lateral view, 18.7-24.8 $\mu \mathrm{m}$ long, 10.5-12.7 $\mu \mathrm{m}$ wide, posterior end rounded, 2 parietal chloroplasts, each with 2 pyrenoids.

Herbarium specimens: BRAZIL. Espírito SAnTo: Cariacica, Duas Bocas Reservoir, surface, 15-VII-1998, A. Delazari-Barroso s.n. (SP356189).

\section{CHRYSOPHYCEAE \\ OCHROMONADALES}

Dinobryaceae

Dinobryon sertularia Ehrenberg, Abh. K. Akad. Wiss. 1833: 280. 1835.

Figure 80

Individuals colonial, lorica campanulate, posterior pole conical, lateral margins smooth, lorica 30.8-37.7 $\mu \mathrm{m}$ long, 9.1-9.2 $\mu \mathrm{m}$ wide.

Herbarium specimens: BRAZIL. EsPíRIto SANTo: Cariacica, Duas Bocas Reservoir, surface, 15-VII-1998, A. Delazari-Barroso s.n. (SP356189).

Among the constant species of cyanobacterias registered in Duas Bocas Resevoir, we pointed out the occurrence of Cylindrospermopsis raciborskii, an invasive and toxic species. C. raciborskii has been reported in many temperate and tropical lakes (Padisák 1997, Briand et al. 2002), including Brazil (Branco \&
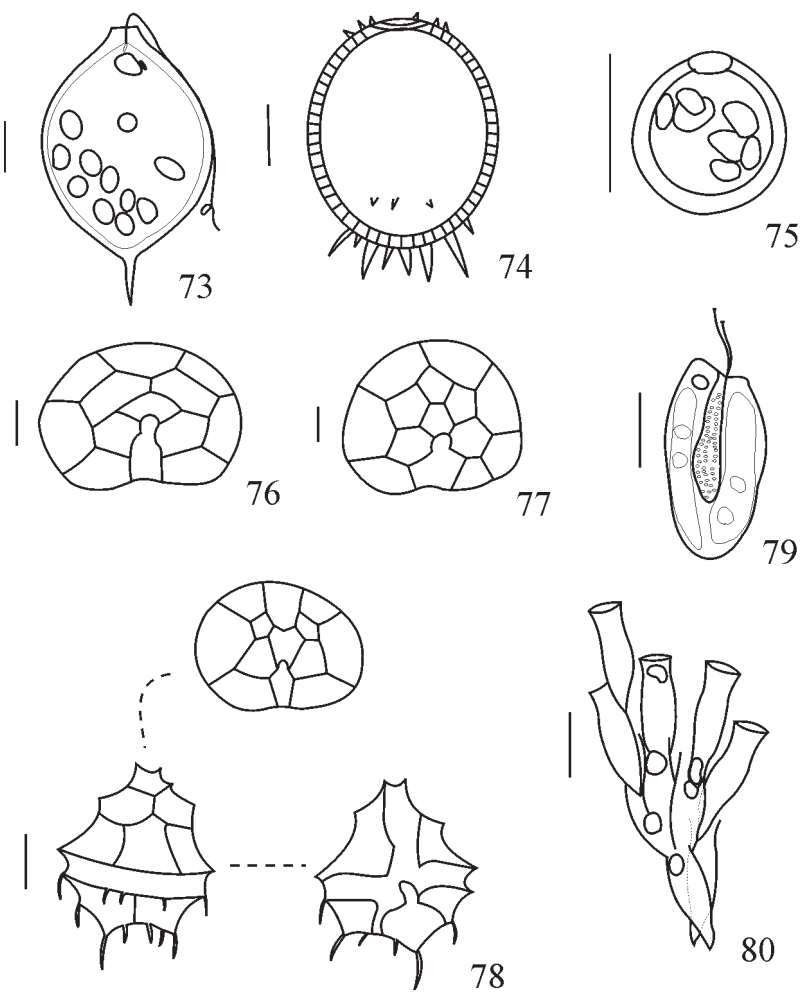

Figure 73. Strombomonas ovalis. 74. Trachelomonas armata var. steinii. 75. T. volvocina. 76. Peridinium africanum. 77. P. gutwinskii. 78. P. umbonatum. 79. Cryptomonas parapyrenoidifera. 80 . Dinobryon sertularia. Scale bars: $10 \mu \mathrm{m}$.

Senna 1994, Lagos et al. 1999, Tucci \& Sant'Anna 2003), and is registered for the first time on a drinking water reservoir in the State of Espírito Santo. Two strains of this species were isolated from this reservoir and toxicological analyses are under development (Delazari-Barroso, unpublished data).

Four species of desmids belonging to the genus Staurastrum were recorded as constant species (table 1). Desmids are turbulence water tolerant species growing mainly in oligotrophic waters (Brook 1981). However, some species of Staurastrum can also grow in eutrophic waters (Reynolds 1987).

Regarding cell size, $25 \%$ of the desmids presented smaller size when compared with literature data (Prescott et al. 1981, 1982). Small cell size, which increases the surface-area-to-volume ratio, and other morphological adaptations, such as complex shapes, enhance the capacity of nutrients uptake and reduce the sedimentation rates in the water column (HappeyWood 1988, Reynolds 1984, 1988). The small size and the high surface-to-volume ratio of the microalgae registered by Huszar (1994) in Amazonian systems were considered as adaptations to low nutrient content waters. 
The majority of coccal green algae presented rare occurrence in this study. These microalgae are turbulence dependent to keep in suspension in water and hence have a disadvantage in stratified waters (Happey-Wood 1988).

Although the occurrence of microalgae is related to several environmental factors, light, temperature and nutrients conditions are the major limiting factors. The geographical distribution is governed by ecophysiological characteristics but also by the floristic knowledge of a region (Comas 1996). In an attempt to classify the life habit and geographical distribution of the species recorded in Duas Bocas Reservoir, we relied on the available literature. Based on this perspective, most of the Chlorococcales and Desmidiales was regard as cosmopolitan species, while the majority of the Cyanobacteria predominantly occur in tropical and temperate lakes and reservoirs. According to Komárek \& Comas (1984), the application of cosmopolitism criterion is influenced by the use of North American and European identification keys on material from tropical areas, which can imply in erroneous identification and classification. To avoid such mistakes, Senna \& Magrin (1999) pointed out the importance of a correct taxonomy, based on population samples, mainly when the floristic data are used on ecological characterization of aquatic systems.

Although most of the species is regarded as planktonic, some typically metaphytic taxa were recorded during rainy period (Cosmarium pseudoconnatum and C. pseudobroomei) suggesting a contribution of cells from riverine areas to the planktonic habitat.

Considering temporal occurrence, eighteen species, mainly coccal green, were registered only during dry period and fourteen species of almost all classes, were recorded only in rainy period (table 1). These data can show a slight trend to higher diversity in turbulence condition, probably because the increase in flux of nutrients from hypolimnion. However, to confirm this hypothesis it is necessary to develop a consistent monthly sampling in an annual basis, and ecological studies on phytoplankton community and nutrient concentrations. In respect of these issues another paper is being prepared.

\section{Acknowledgments}

This research was financially supported by Fundo de Ciência e Tecnologia da Prefeitura Municipal de
Vitória (FACITEC - PMV) and Coordenação de Aperfeiçoamento de Ensino Superior (CAPES). We thank to Instituto de Defesa Agropecuária e Florestal do Espírito Santo (IDAF - ES) for allows the access to Duas Bocas Biological Reserve and to Departamento de Ecologia e Recursos Naturais da Universidade Federal do Espírito Santo (DERN UFES) for the logistic support. We also thank to two anonymous reviewers for providing helpful suggestions on the manuscript.

\section{Literature cited}

Anagnostidis, K. \& Komárek, J. 1989. Modern approach to the classification system of cyanophytes, 4 : Nostocales. Algological Studies 56: 247-345.

Barroso, G.F. \& Marchioro, E. 1999. Estudo de parâmetros morfométricos e sólidos em suspensão em bacias hidrográficas como subsídios ao planejamento ambiental: estudo de caso das sub-bacias do rio Duas Bocas (ES). In: UFMG/CNPq/FAPEMIG (eds.). Anais do VIII Simpósio Brasileiro de Geografia Física Aplicada, Belo Horizonte, pp. 35-42.

Bourrelly, P. 1981. Les algues déau douce: initiation à la systématique, 2: les algues jaunes et brunes. Éditions N. Boubée, Paris.

Bourrelly, P. 1985. Les algues déau douce: initiation à la systématique, 3: les algues bleues et rouges. Éditions N. Boubée, Paris.

Branco, C.W.C. \& Senna, P.A.C. 1994. Factors influencing the development of Cylindrospermopsis raciborskii and Microcystis aeruginosa in the Paranoá Reservoir, Brasília Brazil. Algological Studies 75: 85-96.

Brazil. 2000. Portaria 518, de 5 de outubro de 2005. Ministério da Saúde.

Briand, J.-F., Robillot, C., Quiblier-Lloberas, C., Humbert, J.-F., Couté, A. \& Bernard, C. 2002. Environmental context of Cylindrospermopsis raciborskii (Cyanobacteria) blooms in a shallow pond in France. Water Research 36: 3183-3192.

Brook, A.J. 1981. The biology of desmids. Botanical Monographs, v. 16. Blackwell Science, Oxford.

Comas, A. 1996. Las Chlorococcales dulciacuícolas de Cuba. Bibliotheca Phycologica, Band 99. J. Cramer, Stuttgart.

Delazari-Barroso, A. 2000. Comunidade fitoplanctônica do reservatório Duas Bocas (Reserva Biológica de Duas Bocas) - ES: variação vertical e temporal em duas épocas distintas. Dissertação de Mestrado, Universidade Federal de São Carlos, São Paulo.

Delazari,A. \& Barroso, G. F. 1998. Variáveis físico-químicas do reservatório da Reserva Biológica de Duas Bocas: estudo preliminar. Cadernos de Pesquisa da UFES 8: 81-92. 
Dias Júnior, C. 1998. Estudo do fitoplâncton em um reservatório de águas ácidas na região litorânea do Espírito Santo (Reservatório Águas Claras, Aracruz, ES). Tese de Doutorado, Universidade Federal de São Carlos, São Paulo.

Dias Junior, C. \& Barroso, G.F. 1998. Limnological studies of coastal lagoons in the south of Espírito Santo State (Brazil). Verhandlunger der internationalen Vereinigung für Theoretische und Angervandte Limnologie 26: 1433-1437.

Föster, K. 1982. Conjugatophyceae: Zygnematales und Desmidiales (excl. Zygnemataceae). In: G. HuberPestalozzi (ed.). Das phytoplankton des Süsswassers: systematik und biologie 8. E. Schweizerbart'sche Verlagsbuchlandlung, Stuttgart, pp. 1-543.

Happey-Wood, C.M. 1988. Ecology of freshwater planktonic green algae. In: C.D. Sandgren (ed.). Growth and reproductive strategies of freshwater phytoplankton. Cambridge University Press, Crambridge, pp. 175-226.

Huszar, V.L.M. 1994. Fitoplâncton de um lago amazônico impactado por rejeito de bauxita (lago Batata, Pará, Brasil): estrutura da comunidade, flutuações espaciais e temporais. Tese de Doutorado, Universidade Federal de São Carlos, São Paulo.

Huszar, V.L.M., Silva, L.H.S. \& Esteves, F.A. 1990. Estrutura das comunidades fitoplanctônicas de 18 lagoas da região do baixo rio Doce, Linhares, Espírito Santo, Brasil. Revista Brasileira de Biologia 50: 585-598.

Komárek, J. \& Anagnostidis, K. 1999. Cyanoprokaryota 1. Teil: Chroococcales. In: H. Ettl, G. Gärtner, H. Heynig, \& D. Mollenhauer (eds.). Sübwasserflora von Mitteleuropa 19. Gustav Fischer Verlag, Stutgart, pp. 1-548.

Komárek, J. \& Anagnostidis, K. 2005. Cyanoprokaryota 2. Teil: Oscillatoriales. In: B.Büdel, L. Krienitz, G. Gärtner \& M. Schagerl (eds.). Sübwasserflora von Mitteleuropa 19. Elsevier Spektrum Akademischer Verlag, München, pp.1-759.

Komárek, J. \& Comas, A. 1984. Areas of distribution od coccal green algae in tropical America, in relation to the Algal Flora of Cuba. Ficologia Latinoamericana 2: 133-167.

Komárek, J. \& Fott, B. 1983. Chlorophyceae (Grünalgen), Ordung: Chlorococcales. In: G. Huber-Pestalozzi, H. Heynig \& D. Mollenhauer (eds.). Das phytoplankton des Sübwassers: systematik und biologie. E. Schweizerbart'sche Verlagsbuchlandlung, Stuttgart, pp. 1-1044.

Lagos, N., Onodera, H., Zagatto, P.A., Andrinollo, D., Azevedo, S.M.F.O. \& Oshima, Y. 1999. The first evidence of paralytic shellfish toxins in the freshwater cyanobacterium Cylindrospermopsis raciborskii, isolated from Brazil. Toxicon 37: 1359-1373.

Lobo, E. \& Leighton, G. 1986. Estructuras comunitarias de las fitocenosis planctonicas de los sistemas de desembocaduras de rios y esteros de la zona central de Chile. Revista de Biologia Marinha 22: 1-29.
Padisák, J. 1997. Cylindrospermopsis raciborskii (Wolosz.) Seenayya et Subba Raju, an expanding, highly adaptative cyanobacterium: worldwide distribution and review of its ecology. Algological Studies 107: 563-593.

Perrone, A. \& Barroso, G.F. 1996. Avaliação preliminar do transporte de sólidos pelo córrego Pau Amarelo (Reserva Biológica de Duas Bocas - ES). In: ABES (ed.). Anais do II Encontro Estadual de Saneamento e Meio Ambiente, Vitória, pp. 1-5.

Popovský, J. \& Pfiester, L.A. 1990. Dinophyceae. In: H. Ettl, J. Gerloff, H. Heynig \& D. Mollenhauer (eds.). Sübwasserflora von Mitteleuropa, 6. Gustav Fischer Verlag, Stuttgart.

Prescott, G.W., Croasdale, H.T., Viniard, W.C. \& Bicudo, C.E.M. 1981. A synopsis of north american desmids. Part II: Desmidiaceae: Placodermae Section 3. University of Nebraska Press, London.

Prescott, G.W., Bicudo, C.E.M. \& Vinyard, W.C. 1982. A synopsis of north american desmids. Part II: Desmidiaceae: Placodermae Section 4. University of Nebraska Press, London.

Reynolds, C. S. 1984. The ecology of freshwater phytoplankton. Cambridge University Press, Cambridge.

Reynolds, C. S. 1987. The response of phytoplankton communities to change lake environments. Schweizzerische Zeitschrift für Hydrobiologie 49: 220-236.

Reynolds, C. S. 1988. Functional morphology and the adaptative strategies of freshwater phytoplankton. In: C. D. Sandgren (ed.). Growth and reproductive strategies of freshwater phytoplankton. Cambridge University Press, Crambridge, pp. 388-433.

Senna, P.A.C., Delazari, A. \& Sant'Anna, C.L. 1999. A new planktic cyanoprokaryotic species, Cyanodictyon tropicalis (Cyanophyceae) from Espírito Santo State (Southeastern), Brazil. Algological Studies 94: 293-303.

Senna, P.A.C., Magrin,A.G.E. 1999. A importância da "boa" identificação dos organismos fitoplanctônicos para os estudos ecológicos. In: M. L.M. Pompêo (ed.). Perspectivas da Limnologia no Brasil. Gráfica e Editora União, São Luís, pp. 131-146.

Tucci, A. \& Sant'Anna, C.L. 2003. Cylindrospermopsis raciborskii (Wolosz.) Seenayya et Subba Raju (Cyanobacteria): variação semanal e relações com fatores ambientais em um reservatório eutrófico, São Paulo, SP, Brasil. Revista Brasileira de Botânica 26: 97-112.

Vollenweider, R.A. \& Kerekes, J. 1980. The loading concept as basis for controlling eutrophication philosophy and preliminary results of the OECD Programme on Eutrophication. Progress in Water Technology 12: 5-38. 